\title{
DIAGNOSIS OF ENDOCRINE DISEASE Drug-induced endocrinopathies and diabetes: a combo-endocrinology overview
}

\author{
E Diamanti-Kandarakis', L Duntas'2, G A Kanakis³, E Kandaraki', N Karavitaki ${ }^{4,5}$, E Kassi', S Livadas7, \\ G Mastorakos ${ }^{8}$, I Migdalis ${ }^{9}$, A D Miras ${ }^{10}$, S Nader ${ }^{11}$, O Papalou' ${ }^{1}$, R Poladian ${ }^{12}$, V Popovic ${ }^{13}$, D Rachon ${ }^{14}$, S Tigas $^{15}$, \\ C Tsigos $^{16}$, T Tsilchorozidou ${ }^{17}$, T Tzotzas ${ }^{18}$, A Bargiota ${ }^{19}$ and M Pfeifer ${ }^{20}$ on behalf of COMBO ENDO TEAM: 2018
}

${ }^{1}$ Department of Endocrinology, Diabetes and Metabolism, Hygeia Hospital, ${ }^{2}$ Endocrine Clinic Evgenidion Hospital, University of Athens, ${ }^{3}$ Department of Endocrinology, Athens Naval \& VA Hospital, Athens, Unit of Reproductive Endocrinology, Athens, Greece, ${ }^{4}$ Centre for Endocrinology, Diabetes and Metabolism, Birmingham Health Partners, ${ }^{5}$ Institute of Metabolism and Systems Research, College of Medical and Dental Sciences, University of Birmingham, Birmingham, UK, ${ }^{6}$ Department of Biological Chemistry, First Department of Internal Medicine, Laikon Hospital Medical School, NKUA, ${ }^{7}$ Endocrine Unit, Metropolitan Hospital, ${ }^{8}$ Endocrine Unit, 2nd Department of Obstetrics and Gynecology, National and Kapodistrian University of Athens, 'Aretaieion' University Hospital, '9Second Medical Department and Diabetes Centre, NIMTS Hospital, Athens, Greece, ${ }^{10}$ Division of Endocrinology Diabetes and Metabolic Medicine, Imperial College London, London, UK, ${ }^{11}$ Department of Internal Medicine-Endocrine Division, McGovern Medical School, Houston, Texas, USA, ${ }^{12}$ Department of Endocrinology, MLH University Hospital, Beirut, Lebanon, ${ }^{13}$ School of Medicine, University of Belgrade, Belgrade, Serbia, ${ }^{14}$ Department of Clinical and Experimental Endocrinology, Medical University of Gdańsk, Gdańsk, Poland, ${ }^{15}$ Department of Endocrinology, loannina University Hospital, loannina, Greece, ${ }^{16} \mathrm{Harokopio}$ University of Athens and HYGEIA Hospital, Athens, Greece, ${ }^{17}$ Private Practice, Endocrinologist, Serres, Greece, ${ }^{18}$ St. Luke's Hospital, Panorama, Thessaloniki, Greece, ${ }^{19}$ Department of Internal Medicine - Endocrinology, University of Thessaly, Larissa, Greece, and ${ }^{20}$ Faculty of Medicine, University of Ljubljana, Ljubljana, Slovenia

Correspondence should be addressed to E Diamanti-Kandarakis Email e.diamanti.kandarakis@ gmail.com

\begin{abstract}
In the currently overwhelming era of polypharmacy, the balance of the dynamic and delicate endocrine system can easily be disturbed by interfering pharmaceutical agents like medications. Drugs can cause endocrine abnormalities via different mechanisms, including direct alteration of hormone production, changes in the regulation of the feedback axis, on hormonal transport, binding and signaling, as well as similar changes to counter-regulatory hormone systems. Furthermore, drugs can interfere with the hormonal assays, leading to erroneous laboratory results that disorientate clinicians from the right diagnosis. The purpose of this review is to cover a contemporary topic, the drug-induced endocrinopathies, which was presented in the monothematic annual Combo Endo Course 2018. This challenging part of endocrinology is constantly expanding particularly during the last decade, with the new oncological therapeutic agents, targeting novel molecular pathways in the process of malignancies. In this new context of drug-induced endocrine disease, clinicians should be aware that drugs can cause endocrine abnormalities via different mechanisms and mimic a variety of clinical scenarios. Therefore, it is extremely important for clinicians not only to promptly recognize druginduced hormonal and metabolic abnormalities, but also to address the therapeutic issues for timely intervention.
\end{abstract}

\section{Invited Author's profile}

Evanthia Diamanti-Kandarakis is a Professor of Internal Medicine and Endocrinology and Chairman of the Department of Endocrinology and Diabetes HYGEIA Hospital in Athens, Greece. Her research interests have focused for the last 25 years on clinical, molecular and environmental aspects of metabolic and hormonal abnormalities in obesity diabetes and polycystic ovarian syndrome.

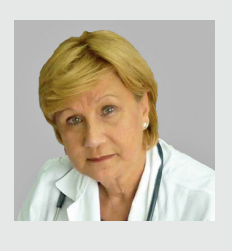




\section{Introduction}

The endocrine system with its precise interactions through multiple mechanisms maintains homeostasis in every system and organ. In the currently overwhelming era of polypharmacy (1), the balance of the dynamic endocrine system can be disturbed by multiple factors like drugs and medications which can lead to endocrine and metabolic abnormalities.

It is estimated that $10 \%$ of the population and $30 \%$ of older adults in the United States are taking five or more drugs systematically $(2,3)$. As a result, drug-related morbidity has been highlighted as a major burden of healthcare systems. In the United States, adverse drug reactions are responsible for four hospitalizations per 1000 people each year (4), with associated annual costs estimated at US\$30 billion (5). Therefore, drugs can be a double-edged sword for our patients' wellbeing and a broadening challenge to our clinical practice.

Drugs can cause endocrine abnormalities via different mechanisms, including direct alteration of hormone production, changes in the regulation of the feedback axis and on hormonal transport, binding, signaling, as well as similar changes to counter-regulatory hormone systems (6). Furthermore, drugs can interfere with the hormonal assays, leading to erroneous laboratory results that disorientate clinicians from the right diagnosis (7).

The purpose of this review is to delineate a 'combo' overview of a contemporary spectrum of drugs, encountered in clinical practice, which induce endocrine and metabolic disorders. In this approach, an effort is made to go beyond a list of adverse effects and via understanding the underlying pathophysiological mechanisms to recognize the drug-induced hormonal and metabolic abnormalities leading to endocrinopathies and diabetes. Conclusively, we aim to raise the clinicians' vigilance in promptly recognizing drug-induced endocrinopathies and diabetes, in order to make it an integral part of clinicians' differential diagnosis, emphasizing the indisputable role of meticulous medical history in order to make the appropriate decision for the therapeutic intervention.

Table 1 summarizes some the most commonly used drug categories that will be analyzed in the following text, along with their broad spectrum of endocrine side effects.

\section{Drug-induced pituitary dysfunction}

\section{Drug-induced hypopituitarism}

The immune therapies in advanced cancers with immune checkpoint (ICP) inhibitors have led to a great relief and
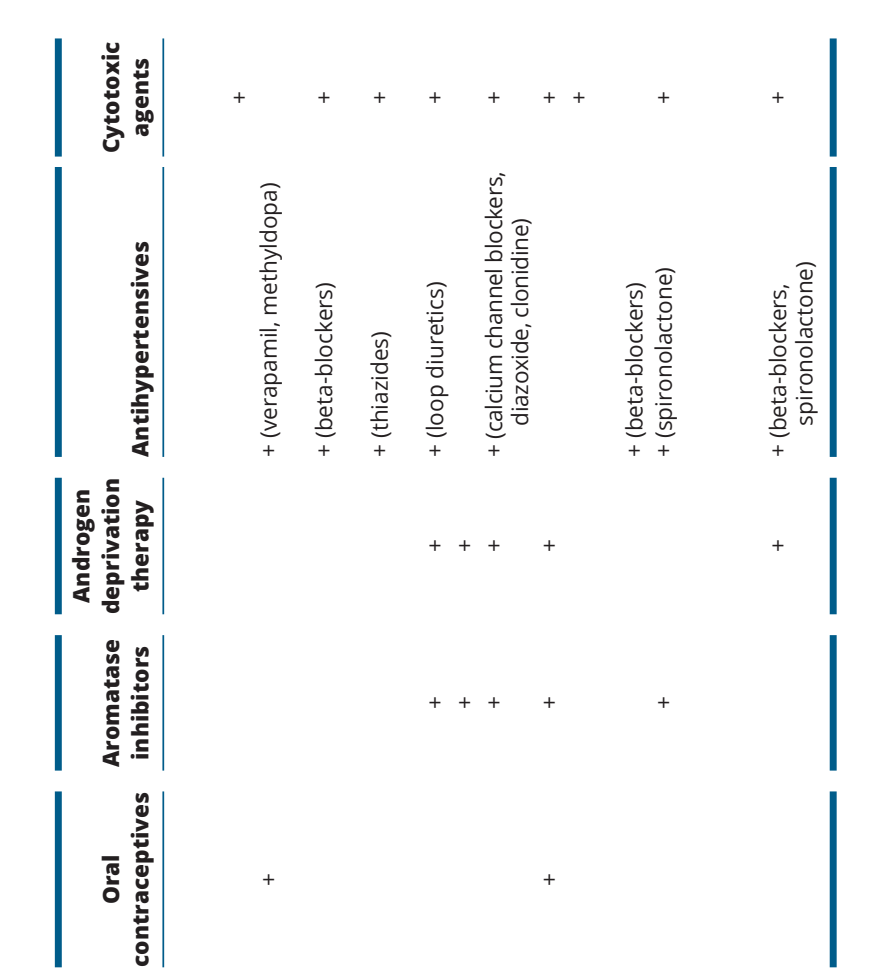
much greater hope in patients and physicians (8). In the past 15 years, ICP inhibitors have emerged as a promising and expanding class of anticancer agents, and their use has resulted in the alteration of the natural history of certain types of cancer $(9,10)$.

Along with the promising results in the patients who respond to these therapies, the modulation of immune response can result in a number of immunerelated adverse events (IRAEs) affecting almost all organ systems. Typically, IRAEs affect the skin, gastrointestinal system, the lung, musculoskeletal, renal and nervous system. Interestingly, endocrine system IRAEs are also commonly involved. The most common of them include hypophysitis and thyroid dysfunction; rare cases of insulin-dependent diabetes mellitus, hypoparathyroidism and primary adrenal insufficiency (adrenalitis) have been reported $(11,12,13,14,15)$.

\section{Autoimmune hypophysitis related to immune checkpoint (ICP) inhibitors}

Immune check point signaling pathways are critical in regulating T-cell activation and immune tolerance. Two pathways seem to be important: CTLA4 checkpoint pathway and PD-1/PD-L1 checkpoint pathway (programmed cell death 1/programmed cell death 1 ligand). Immune checkpoint proteins are T-cell surface receptors that serve in maintaining the immune selftolerance and preventing the development of autoimmune disorders $(9,10)$. The first signal of the normal T-cell activation involves the binding of a T-cell receptor to the major histocompatibility complex (MHC) presenting an antigen on an antigen-presenting cell (APC). The second signal involves the binding of a T-cell CD28 receptor to the $\mathrm{B} 7$ ligand on the APC. CTLA4 receptors on the surface of $\mathrm{T}$ cells are able to compete with CD28 for binding to the B7 ligands, thus inhibiting T-cell-mediated immune responses. ICP inhibitors are monoclonal antibodies that block the proteins from binding to the tumor cells and APCs, thereby taking off the brake and allowing the T-cell to recognize and attack the tumor cells (Fig. 1).

The use of CTLA4 and PD1/PDL1 antibodies allows the activation of $\mathrm{T}$ lymphocytes who set sight on the endocrine glands causing thyroid dysfunction in 15\%, hypophysitis in $9-11 \%$, adrenalitis in $1 \%$ and diabetes type 1 in $1 \%(11,16,17,18)$. The incidence of hypophysitis after treatment with CTLA-4 antibodies (ipilimumab, tremelimumab) is about $11-12 \%$ and is rarer with drugs targeting PD-1 (nivolumab, pembrolizumab) and PDL1 (atezolizumab, durvalumab, avelumab). Recently, the first report on central diabetes insipidus associated with anti-PDL1 treatment has been published (19). ICP inhibitor-induced anterior pituitary hypophysitis presents insidiously with subtle symptoms and with mild-to-moderate pituitary enlargement. Headache and fatigue are the leading symptoms. Most endocrinologists are seeing these patients as a result of referrals from oncologists because of low T4 and TSH. The majority of endocrinopathies are identified with hormonal screening, as most symptoms are typically related to cancer, masking the symptoms of endocrinopathies. (Fig. 1). Rarely, its clinical presentation may be acute, with headache, vomiting and visual field defects, requiring prompt therapeutic management.
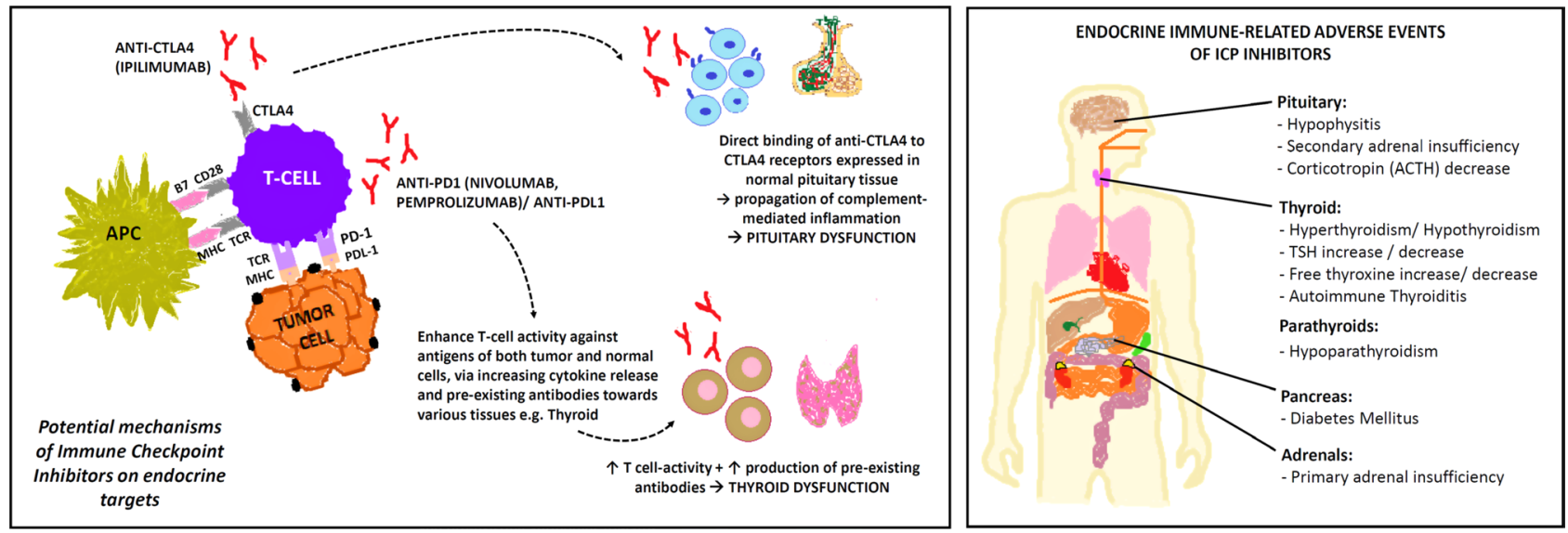

\section{Figure 1}

Potential mechanisms of CTLA-4 and PD-1/PDL-1 antibodies involved in antitumor immune responses, as well as in major endocrine targets, translated into the main endocrine adverse associated with immunotherapy. 
Anterior pituitary hypophysitis is accompanied with hypopituitarism. Not so rarely, isolated adrenocorticotropic hormone (ACTH) deficiency may be observed in these patients. Analogously, isolated interruption of TSH synthesis and secretion can be observed, as well. Apart from immunotherapy, there is a respectable subset of drugs that suppresses TSH either at the level of pituitary or hypothalamus (Table 2). Not all cause clinically significant central hypothyroidism. Glucocorticoids, somatostatin analogs and dopamine agonists suppress TSH but do not cause clinically significant hypothyroidism, while rexinoids (bexarotene) induce clinically significant central hypothyroidism, which requires replacement with levothyroxine (20). Metformin lowers TSH in diabetic patients with concomitant hypothyroidism (21). However, when metformin effect on TSH was studied in patients with subclinical hypothyroidism in a randomized, double-blind, placebo-controlled clinical trial, no significant reduction of TSH was found between the placebo and the metformin group (22).

Recovery from pituitary deficiencies is variable. ACTH deficiency persists in $86-100 \%$ of cases, while $13-36 \%$ of patients continue to have TSH deficiency and $13-53 \%$ a gonadotropin deficiency $(18,23)$. Features of hypocortisolism may be vague, such as nonspecific tiredness (24). A case of transient ACTH-dependent Cushing syndrome, which appeared after combined ipilimumab and nivolumab therapy, was characterized by spontaneous regression of hypercortisolism and subsequent appearance of severe corticotroph deficiency (25). Morning cortisol should be measured in a patient receiving ICP inhibitors who is unwell. Acute cortisol deficiency may be life-threatening and early recognition and appropriate management is essential. Recent UK guidelines present endocrine assessment and management of acute life-threatening endocrine complications of ICP inhibitor therapies (26). Glucocorticoid replacement is suggested with the usual replacement dose of hydrocortisone $(10+5+5 \mathrm{mg})$ or $7.5 \mathrm{mg}$ prednisolone. Short-term higher doses of glucocorticoids might be beneficial for patients with visual field defects, severe hyponatremia, cranial nerve palsies and in some cases of intractable headache. Newer studies suggest that higher doses of glucocorticoids may negatively affect the antitumor efficacy of ICP inhibitors (27). Hormone deficiencies may improve except for corticotroph function. Immunotherapy can be continued once the patient is clinically stable on appropriate endocrine replacement therapy. Overall survival of patients with ipilimumabinduced hypophysitis is better versus patients without hypophysitis as shown in Fig. 2.

As for the underlying pathophysiology of ICP inhibitor-induced hypophysitis, it has been postulated that pituitary immunogenicity is mediated by CTLA-4 antigen expression by pituitary endocrine cells. This leads to complement activation and infiltration of macrophages (type II hypersensitivity reaction) and autoreactive T lymphocytes (type IV hypersensitivity reaction) $(28,29,30,31)$. The susceptibility of pituitary cells to ICP inhibitors has been recently nicely demonstrated in a patient with pituitary carcinoma resistant to all available treatments including temozolomide but responding robustly to combination ICP inhibitor therapy (32).

Conclusively, although there is great promise in immunotherapies we must not let excitement of such treatments overshadow the potential problems (33). Early recognition and appropriate management of immune-mediated endocrinopathies, and specifically

Table 2 Drug-induced suppression of TSH and underlying pathogenetic mechanisms.

\begin{tabular}{|c|c|c|}
\hline Drug class & Mechanism of action & Clinically significant hypothyroidism \\
\hline \multicolumn{3}{|c|}{ Drug-induced suppression of TSH and underlying pathogenetic mechanisms } \\
\hline Glucocorticoids & $\begin{array}{l}\text { Activation of glucocorticoid receptor. } \\
\text { Inhibition of TRH synthesis/secretion. }\end{array}$ & No \\
\hline Dopamine agonists & $\begin{array}{l}\text { Activation of dopamine receptors (D2) on } \\
\text { thyrotropes. } \\
\text { Reduced TSH pulse amplitude. }\end{array}$ & $\begin{array}{l}\text { Probably not. } \\
\text { May cause hypothyroidism in patients } \\
\quad \text { with euthyroid sick syndrome. }\end{array}$ \\
\hline Somatostatin analogs & $\begin{array}{l}\text { Activation of somatostatin receptors in } \\
\text { thyrotropes. } \\
\text { Inhibition of TSH secretion. } \\
\text { Probable altered thyroid hormone metabolism }\end{array}$ & No \\
\hline Rexinoids & $\begin{array}{l}\text { Activation of retinoid X receptor (RXR). Inhibition } \\
\text { of TSH } \beta \text { transcription in the pituitary. } \\
\text { Increased peripheral metabolism of thyroid } \\
\text { hormone }\end{array}$ & Yes \\
\hline
\end{tabular}




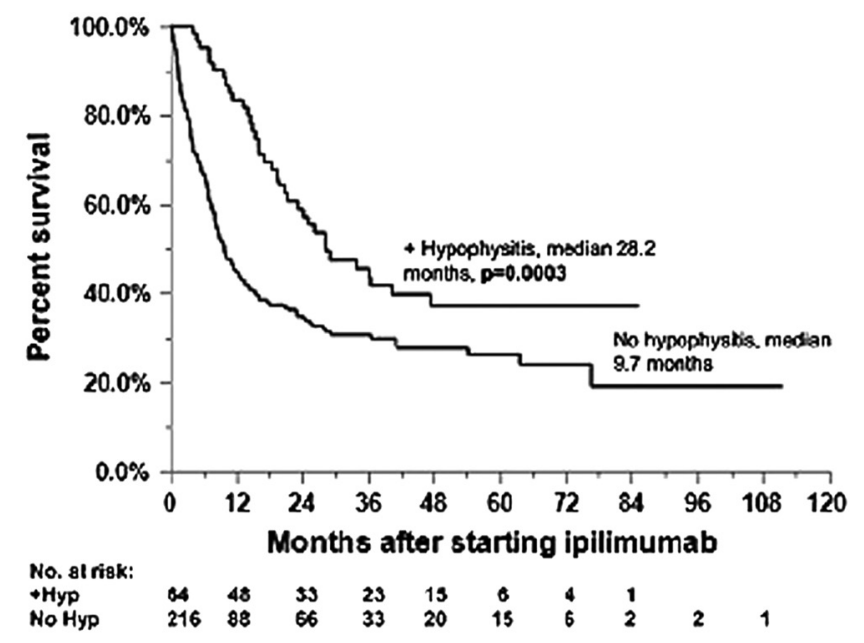

Figure 2

Overall survival is illustrated after ipilimumab monotherapy in patients who had hypophysitis (1 Hyp) versus patients without hypophysitis Reproduced from Faje et al. (27), Copyright (2018) with permission from John Wiley and Sons.

hypophysitis, is essential. Once the patient is clinically stable on appropriate endocrine replacement therapy, immunotherapy can be safely continued.

\section{Drug-induced syndrome of inappropriate antidiuretic hormone secretion (SIADH)}

SIADH is a common cause of hyponatremia with corresponding hypo-osmolality, absence of volume depletion or of other causes of hyponatremia (normal thyroid and adrenal, no diuretics) (34). Drugs are a common cause of SIADH. Selective serotonin reuptake inhibitors and carbamazepine are the most commonly implicated drugs associated with SIADH. In a retrospective single-center study, which included 198 patients diagnosed with SIADH, five drug classes were found to be implicated in $82.3 \%$ of those patients, including antidepressants, anticonvulsants, antipsychotic drugs, cytotoxic agents, pain medications and ecstasy (35). The clinical characteristics of drug-induced SIADH are comparable between different medication classes.

The mechanisms of drug-induced SIADH include inappropriate levels of vasopressin in the state of hypoosmolality or increased expression of the water channel aquaporin-2 in renal collecting duct (34). The major predisposing risk factors are the patient's age, as well as the serum levels of the drug. Strategies to improve management are earlier recognition of patients with chronic hyponatremia and subtle neurological symptoms (inability to concentrate, memory problems, mental irritability, dowsiness), better analysis of predisposing factors, monitoring and treatment of hyponatremia with fluid restriction or the use of vasopressin-receptor antagonists (vaptans) (36). No known genetic risk variants for carbamazepine or oxcarbazepine-induced hyponatremia exist, but likely candidate genes are part of the vasopressin water reabsorption pathway (37).

\section{Drug-induced hyperprolactinemia}

For the practicing endocrinologist, hyperprolactinemia is a common laboratory finding and very often it is due to the use of certain medications. Elevation of serum prolactin (PRL) concentrations above $25 \mu \mathrm{g} / \mathrm{L}(1 \mu \mathrm{g} / \mathrm{L}=21.2 \mu \mathrm{UI} / \mathrm{mL})$ is very often encountered during the 'hormonal check-up' of a female patient and in most cases is not related to the hypothalamic or pituitary pathology. Therefore, measurement of serum PRL levels should only be performed in patients who have clinical signs of hyperprolactinaemia such as menstrual irregularities, fertility problems, galactorrhea or benign breast disease in women or signs of androgen deficiency (i.e. loss of libido or erectile dysfunction) in men.

When assessing a patient with symptomatic hyperprolactinemia and before performing the magnetic resonance imaging (MRI) of the pituitary one must always exclude the potential effects of medications, which lead to the excessive PRL production. By looking at the mechanisms, which govern the secretion of PRL, it is obvious that all the drugs possessing dopamine D2 receptor antagonistic effects will cause significant hyperprolactinemia (38). Nevertheless, the most frequent cause of a drug-induced hyperprolactinemia is due to the use of estrogen-containing oral contraceptives (OCs) (39, 40). These drugs, which usually contain the potent estrogen ethynylestradiol are very often the cause of a moderate hyperprolactinemia $(<100 \mu \mathrm{g} / \mathrm{L})$. These cases usually do not require treatment but should be re-evaluated after the cessation of the OCs use. Nevertheless, it must be stressed that after the withdrawal of OCs mild elevation of serum PRL levels might also be observed as in the case in women after pregnancy (in the post-partum period) (41).

When the mechanism of drug-induced hyperprolactinemia are due to the inhibition of dopamine action (dopamine receptor antagonists), serum PRL concentrations are significantly elevated and in some cases can also reach values over $200 \mu \mathrm{g} / \mathrm{L}$ (42). The most common are the typical antipsychotics (i.g. phenothiazines or butyrophenones) and risperidone or 
its analogs $(43,44)$. Nevertheless, drugs such as tricyclic antidepressants (i.e. doxepin and amitriptyline), selective serotonin reuptake inhibitors (i.e. fluoxetine, paroxetine, sertraline, citalopram, fluvoxamine), antihypertensives (i.e. verapamil, methyldopa) and opiates (i.e. tramadol, buprenorphine, methadone) can also cause moderate elevations of serum PRL concentrations $(45,46,47,48)$. The drugs are listed in Table 3.

In order to rule out drug-induced hyperprolactinemia, it is recommended to discontinue the medication for at least 3 days or substitute it with an alternative drug and then re-evaluate serum PRL concentrations. If the discontinuation of the drug is not possible or the onset of hyperprolactinemia does not correspond with its initiation, a MRI of the pituitary should be performed in order to rule out the presence of a pituitary or a para-sellar mass (41).

When asymptomatic, drug-induced hyperprolactinaemia usually does not require treatment. If symptomatic (i.e. galactorrhea, amenorrhea, bone loss or androgen deficiency symptoms in men), it is recommended to substitute for a drug with similar action, which does not cause hyperprolactinaemia (i.e. aripiprazole - an antipsychotic drug with both dopamine agonist and antagonist activity) (49). If this is not possible one might consider the cautious administration of a dopamine agonist (i.e. bromocriptine or cabergoline), however, always in consultation with the patient's psychiatrist. Dopamine agonists have been shown to normalize serum PRL concentrations of such patients but on the other hand pose a risk of the exacerbation of the psychotic symptoms (50). When the signs of hypogonadism related to the drug-induced hyperprolactinaemia are evident (i.e. amenorrhea in women or androgen deficiency symptoms in men) or there is an increased risk of bone loss, it is recommended to add estrogen or testosterone replacement therapy (51). Asymptomatic, drug-induced hyperprolactinaemia usually does not require treatment.

\section{Opiate-induced endocrinopathies}

Opioids include the naturally occurring alkaloids of opium or synthetic chemicals that bind to opioid receptors. Their effects are generated after binding to G-protein-coupled receptors and in clinical practice, they are mainly used as analgesic agents. Heroin is used as a recreational drug due to its euphoric effects (illicit use). The use of opioids has risen substantially in the last two decades, between 2000 and 2014 , it increased by $216 \%$ in USA and $210 \%$ globally (52). Exogenous opioids can have various effects on the endocrine system, and we will focus on the most clinically significant ones (hypothalamo-pituitary-gonadal and hypothalamo-pituitary-adrenal axes).

\section{Hypothalamo-pituitary-gonadal axis}

Studies on healthy human volunteers and on patients using opioids for therapeutic purposes or as medicationassisted addiction treatment or as a drug of abuse and dependence have shown their suppressive action on the hypothalamo-pituitary-gonadal (HPG) axis (53, 54). The pathophysiological mechanism involves reduction of the release or disruption of the normal pulsatility of gonadotropin-releasing hormone (GnRH) secretion from the hypothalamus, as well as decrease of the

Table 3 Drugs inducing moderate or significant hyperprolactinemia.

\begin{tabular}{|c|c|}
\hline Drug class & Drugs \\
\hline \multicolumn{2}{|c|}{$\overline{\text { Drugs causing moderate hyperprolactinemia (PRL }<100 \mu \mathrm{g} / \mathrm{L})}$} \\
\hline Estrogens & OCs \\
\hline \multicolumn{2}{|l|}{ Estrogen replacement therapy } \\
\hline Tricyclic antidepressants & Doxepin, Amitriptyline \\
\hline Selective serotonin reuptake inhibitors & Fluoxetine, Paroxetine, Sertraline, Citalopram, Fluvoxamine \\
\hline Antihypertensives & Verapamil, Methyldopa \\
\hline Opiates & Tramadol, Buprenorphine, Methadone \\
\hline \multicolumn{2}{|c|}{ Drugs causing significant hyperprolactinemia (PRL > $200 \mu \mathrm{g} / \mathrm{L})$} \\
\hline \multirow[t]{3}{*}{ Antipsychotic drugs } & $\begin{array}{l}\text { Phenothiazines (chlorpromazine, levomepromazine, perphenazine, } \\
\text { thiorydazine) }\end{array}$ \\
\hline & Butyrophenones (haloperidol, benperidol) \\
\hline & Risperidone, Paliperidone \\
\hline First generation anti-histamines & Promethazine (phenothiazine derivative) \\
\hline Anti-emetics & Domperidone (butyrophenone derivative) \\
\hline & Metoclopramide \\
\hline
\end{tabular}

OCs, oral contraceptives. 
release of gonadotrophins from the pituitary gland and of testosterone or estradiol from the gonads $(53,55)$. Negative effects of opioids on the kisspeptin-induced rise in the luteinizing hormone (LH) pulse amplitude may also be implicated (56). Hyperprolactinemia that has been occasionally found in opioid users, also contribute to the suppressive effects on the HPG axis (53). Direct actions on the gonads have also been reported with reduction in the production of sperm, testicular interstitial fluid and intratesticular testosterone (57).

The reported prevalence of hypogonadism ranges between 21 and $86 \%$ (55). The initial studies on this field involved heroin addicts and patients on methadone for maintenance and had shown decrease in testosterone levels in males, as well as reduction in LH and/or follicle-stimulating hormone (FSH) (58). Amenorrhea and galactorrhea in female heroin addicts have been described in one case series (59), but series systematically assessing this group are not available. Hypogonadism has also been found in patients of both sexes on opioids (oral, transdermal or intrathecal) for cancerous or non-cancerous pain (55). The hormonal changes start as soon as the opioid is taken and they are dose related $(60,61,62,63)$. Clinical manifestations include erectile dysfunction, decreased libido, infertility, fatigue, depression, hot flushes and night sweats in males and reduced libido, ameno- or oligomenorrhea with anovulation in premenopausal females. It is of note that chronic use of long-acting opioids is associated with greater odds of androgen deficiency compared to chronic use of short-acting ones $(63,64)$. Reduction in the dose or cessation of opioid leads to reversal of hypogonadism $(65,66,67)$, but the time course of this has not been systematically assessed.

\section{Hypothalamo-pituitary-adrenal axis}

Opioids suppress the hypothalamo-pituitary-adrenal (HPA) axis mainly at the hypothalamic-pituitary level by inhibiting corticotrophin-releasing hormone (CRH) and vasopressin secretion and by reducing their effect on ACTH and cortisol release (55). It has been shown that even single administration of various opioids in normal subjects suppresses ACTH and glucocorticoid secretion, leads to blunted pituitary-adrenal response to CRH and diminished cortisol response to psychosocial or surgical stress $(68,69,70)$.

Although several case reports documenting secondary adrenal insufficiency after oral or transdermal opioid administration have been published $(66,67,71,72)$, the accurate prevalence of adrenal insufficiency in these patients has not been clearly defined. Gibb et al., in a series of 48 patients attending chronic tertiary pain clinics and treated with long-term opioid analgesia for at least 6 months and no recent exposure to exogenous glucocorticoids, found failure to respond to synthetic ACTH stimulation in 6\% (73). Abs et al. in a series of 72 patients on intrathecal administration of morphine or hydromorphine reported peak cortisol $<18 \mu \mathrm{g} / \mathrm{dL}$ on insulin tolerance test (ITT) in 15\% (62).

Factors predicting compromised cortisol stress response have not been as yet established. Nonetheless, given, the widespread use of opioids, a large number of patients are possibly on risk of cortisol deficiency. The altered HPA axis function of opioid users improves or returns to normal after discontinuation or reduction in the dose of the opioid $(53,72,73)$, but the interval of this has not been systematically reviewed. Although an evidencebased guidance is not available, patients on opioids should be considered at risk of hypoadrenalism and checking an early morning plasma cortisol (particularly if relevant clinical manifestations are present) is advised. Further dynamic assessment of the HPA axis will depend on the results of the basal cortisol.

\section{Drug-induced thyroid abnormalities}

\section{Thyroid dysfunction secondary to cancer immunotherapy}

In patients treated with ICP inhibitors, thyroid dysfunction can be primary or secondary (related to hypophysitis), and it is therefore important for the clinician to distinguish between the two entities. It is possible that disruption of immune tolerance via PD1/PDL1 is responsible for the development of thyroid IRAEs; however, the exact mechanisms remain unclear. It has been hypothesized that polymorphisms in the CTLA-4, PD1 or PDL1 genes may lead to a higher incidence of autoimmune thyroid disorders and hypophysitis $(15,74,75,76)$. Whether the presence of thyroid autoantibodies has a pathogenetic role is also unclear, although an increase in thyroid antibodies has been reported in patients with pembrolizumab-induced thyroiditis (77). In another report, pembrolizumab-induced thyroiditis was thought to be mediated by circulating CD56, CD16 and NK cells (15).

Primary thyroid dysfunction is usually related to painless thyroiditis presenting with an initial phase of 
thyrotoxicosis due to the release of thyroid hormone as a result of thyroid gland inflammation, followed by a hypothyroid phase. As the thyrotoxic phase is commonly asymptomatic, it may be missed and the patient may present with primary hypothyroidism (i.e. with an elevated TSH and low or normal free T4). The diagnosis of secondary (central) hypothyroidism is on other hand suspected when the free T4 level is low and TSH is low or low-normal. Graves' orbitopathy with or without associated hyperthyroidism may rarely occur $(78,79,80)$.

The incidence of primary hypothyroidism with CTLA4 antibody treatment (ipilimumab) ranges from 5.2 to $5.9 \%$, with 'thyroiditis' been reported in $3.2 \%$, whereas secondary hypothyroidism due to hypophysitis is more common $(7.6 \%)(10,11,14,17)$. With PD1/PDL1 inhibitor use, primary hypothyroidism is observed in 5.9/4.3\% and primary hyperthyroidism in 3.3\% of cases (10). When both classes of ICIs are used in combination, thyroid dysfunction (of any cause) is even more common, with a mean incidence of $13.9 \%$ for hypothyroidism and $8.0 \%$ for hyperthyroidism, in earlier studies $(81,82,83,84)$. More recent studies report rates of primary thyroid dysfunction as high as 14-20\% with combination ICP inhibitors treatment (74). The natural history of ICP-related thyroiditis was studied in a recent large retrospective study from MD Anderson Cancer Center (85); 657 patients with normal baseline thyroid function who developed thyrotoxicosis due to ICP inhibitors use were included. Overall, 84\% of patients developed hypothyroidism and only $9 \%$ eventually recovered from transient hypothyroidism. The median time to thyrotoxicosis was 5.3 weeks $(0.6-19.6)$ and the median time to hypothyroidism was 10.4 weeks (3.4-48.7). The majority of patients in this study were asymptomatic during the thyrotoxic phase and no patient had to discontinue ICI treatment (85). In an analogous study by Lee et al., it was confirmed that thyroiditis is the most common thyroid disorder induced by ICP inhibitors use. The time to onset of thyrotoxicosis after treatment initiation and evolution of thyrotoxicosis to hypothyroidism was short, emphasizing the importance of close monitoring of thyroid function in these patients (86).

Recent oncology guidelines provide detailed guidance on appropriate screening and management of endocrine IRAEs; regular thyroid function testing is recommended every $4-6$ weeks $(87,88)$. Endocrine consultation is advised for patients who develop thyroiditis or hypophysitis. During the thyrotoxic phase, before progression to hypothyroidism, no specific treatment is usually required. In patients with symptoms such as tachycardia or tremor, symptomatic treatment with $\beta$-blockers may be used. Glucocorticoids are not routinely recommended. Thyroid replacement with levothyroxine is indicated for patients who develop hypothyroidism. The median dose of levothyroxine in one recent study, was $1.2 \mu \mathrm{g} / \mathrm{kg}$ (as compared to the usual dose of $1.6 \mu \mathrm{g} / \mathrm{kg}$ in other forms of primary hypothyroidism) (85). Lower starting doses (25$50 \mu$ g daily) should be used in elderly or fragile patients. Adrenal dysfunction should always be replaced before thyroid therapy is initiated to prevent Addisonian crisis. Importantly, cancer immunotherapy does not usually need to be discontinued, unless the patient's symptoms are severe and the event is CTACAE (Common Terminology Criteria for Adverse Events) grade $\geq 3$, in which case ICI therapy can be withheld and restarted when the grade has improved to $<1$. For persistent hyperthyroidism or when there is clinical suspicion, measurement of thyroidstimulating immunoglobulin (TSI) or TSH receptor antibodies (TRAbs) and thyroid scintigraphy may be arranged to rule out Graves' disease. When secondary hypothyroidism develops as a result of hypophysitis, recovery is possible (in 6-64\% of cases), whereas secondary adrenal insufficiency is usually permanent.

Apart from cancer immunotherapy, alemtuzumab, a monoclonal antibody used in multiple sclerosis (MS) has also been associated with thyroid dysfunction. Specifically, TRAb-positive hyperthyroidism is reported with a frequency of $20-30 \%$ in these patients, with its management being similar to 'wild-type' Graves' disease (89).

\section{Tyrosine kinase inhibitors-induced thyroid disorders}

Tyrosine kinase inhibitors (TKIs) have been established as a crucial therapeutic stepping stone in anticancer therapy. Via targeting different receptors, they manage to attenuate cancer cell survival and growth, invasiveness and angiogenesis in multiple cancer entities. One of the most common side effect of TKIS is thyroid dysfunction, accompanied by an important prognostic value, as median progression-free survival and overall survival has been shown to be much better in patients who developed hypothyroidism on TKI therapy, as compared to patients who remained euthyroid (90).

Many mechanisms with respect to this adverse effect have been proposed including their induction 
of thyroiditis, capillary regression in the thyroid gland, antithyroid peroxidase antibody production and their ability to decrease iodine uptake by the thyroid gland (91). Thus, TKI therapy should be accompanied by a thyroid hormonal evaluation before their initiation, as well as monitor thyroid function during and after the end of treatment (92).

\section{Psychotropics-induced thyroid abnormalities}

Despite their potent effect in various psychiatric disorders, psychotropic drugs, particularly antidepressants and antiepileptics may induce thyroid dysfunction. In a study looking into the risk of hypothyroidism over 4 years of treatment, the cumulative risk of hypothyroidism for lithium (8.8\%) was 1.39-fold that of the therapy presenting the lowest risk with oxcarbazepine (6.3\%) (93). Lithium conferred a higher degree of risk for hypothyroidism when compared with other treatments (lamotrigine, valproate, oxcarbazepine or carbamazepine) or antipsychotics (aripiprazole, olanzapine, risperidone or quetiapine) (93). Lithium is usually effective either as monotherapy or as combined treatment. However, the drug may rapidly, within 3-4 weeks, induce goiter by inhibiting thyroid hormone secretion and increasing TSH, particularly in females and also dependent on dose and duration of treatment $(94,95)$. It was shown in different cell lines that lithium activates canonical Wnt signaling and inhibits GSK-3beta, suggesting a crucial role of Wnt/ beta-catenin signaling in lithium-dependent thyrocyte proliferation (96).

Furthermore, a recent cross-sectional study including 298 patients with epilepsy, 52 (17.4\%) showed low fT4 with older age $(P=0.004)$, female sex $(P=0.014)$, longer duration of epilepsy $(P=0.001)$ and intractable epilepsy $(P=0.009)$, which is strongly associated with low fT4 (97). The drugs carbamazepine (30.1\%), topiramate $(28.6 \%)$ and levetiracetam $(24.3 \%)$ or a combination of more than three drugs was significantly associated with decreased thyroid function. Based on these findings and other studies, it is recommended that patients under antiepileptics should be monitored for thyroid dysfunction.

In the event of undiagnosed hypothyroidism, even of a mild degree, a higher risk of serotonin syndrome or of neuroleptic malignant syndrome (NMS) may be documented (98). Serotonin syndrome is caused by drugs that inhibit the release or the reuptake of serotonin, serotonin-norepinephrine reuptake inhibitors (SNRIs), selective serotonin reuptake inhibitors (SSRIs), as well as monoamine oxidase inhibitors (MOI), which retards the catabolism of 5-HT by inhibiting the catalytic enzyme monoamine oxidase (97). Given that reduced 5-HT responsiveness and increased 5-HT turnover in the brainstem have been reported in hypothyroid patients, it is conjectured that severe hypothyroidism may impair the degradation of 5-HT (99). Simultaneously, while primary hypothyroidism is thought to predispose to NMS by altering dopamine activity in central tracts susceptible to neuroleptics blockade (98), thyroid hormone administration could completely reverse the clinical picture. It is thus recommended that patients under psychotropic drug treatment and whose clinical picture is unclear should have their thyroid function assessed.

\section{Amiodarone-induced thyroid disorders: therapeutic particularities}

Amiodarone is a potent antiarrhythmic drug with a number of side effects, including thyroid dysfunction. Thyroid abnormalities have been noted in up to $14-18 \%$ of patients receiving long-term amiodarone therapy. However, a meta-analysis suggested that with the lower doses of amiodarone (150-330 mg) the incidence of thyroid dysfunction is $3.7 \%$. The effects range from abnormal thyroid function tests to overt thyroid dysfunction, which may be either amiodaroneinduced thyrotoxicosis (AIT) or amiodaroneinduced hypothyroidism (AIH) $(100,101,102)$. Both pathologies can develop in apparently normal thyroid glands or in glands with preexisting abnormalities. Pathophysiologically, amiodarone effects in the thyroid gland and its metabolism are both unique and quite complex and occur via a number of differing mechanisms. Thyroid dysfunction linked to amiodarone is not only related to iodine overload, secondary to the exposure of increased iodine levels from amiodarone, but also to the intrinsic effects of amiodarone to the thyroid hormone metabolism (102) (Tables 4 and 5).

\section{Drug-induced bone and calcium metabolism deregulation}

\section{Drug-induced deregulation of calcium and vitamin D metabolism}

More and more drugs have been found to interact with vitamin $\mathrm{D}$ and calcium metabolism affecting bone health of patients and making this topic of increasing interest. 
Most of these drugs act through the pregnane $\mathrm{X}$ receptor (PXR) to mediate their effects on vitamin D metabolism.

PXR is a nuclear receptor, which is expressed in various tissues among them the gastrointestinal tract, kidneys and liver and shows 63\% homology with the vitamin $\mathrm{D}$ receptor in the DNA-binding domain. Thus, it can bind to vitamin D-responsive elements (VDREs) at the promoter of genes that are normally regulated by vitamin $\mathrm{D}$, such as those encoding enzymes which are implicated in the metabolism of vitamin D. A long list of drugs can affect vitamin D metabolism acting mainly as PXR ligands among them, antiepileptic, antiretroviral, antineoplastic (taxol, cyclophosphamide), antihypertensive (nifedipine) and antibiotics (cotrimoxazole, rifampicin) (103). It is of

Table 4 Amiodarone basic characteristics and properties.

Amiodarone characteristics

- Amiodarone is derived from Amphiphilic Benzofurane, with a long plasma half life, ranging from 30 to 100 days.

- lodine comprises $37 \%$ of its molecular weight, $8-17 \%$ of which is released as free lodide.

- Highly lipophilic, concentrates in adipose tissue, muscles, liver, lungs, cornea \& thyroid gland mainly.

- Inhibits type 15'-deiodinase enzyme activity, thereby decreasing the peripheral conversion of T4 to triiodothyronine (T3) and reducing the clearance of both T4 and reverse T3 (rT3). Consequently, the serum levels of T4 and rT3 increase and the serum levels of T3 decrease by $20-25 \%$.

- Inhibits entry of T4 and T3 into the peripheral tissue, via inhibiting thyroid hormone transport across the plasma membrane, and via directly binding to the thyroid hormone receptors. Serum T4 levels increase by an average of $40 \%$ above pretreatment levels after 1-4 months of treatment with amiodarone.

- Inhibition of type $25^{\prime}$-deiodinase enzyme activity in the pituitary due to feedback mechanism is observed in the first 1-3 months and leads to an increase in thyroidstimulating hormone (TSH) levels. This is not an indication for T4 replacement in these patients. Serum TSH levels return to normal in 2-3 months as T4 concentrations rise sufficiently to overcome the partial block in T3 production.

- The response of TSH to TRH may be reduced.

- Amiodarone and its metabolites may have a direct cytotoxic effect on the thyroid follicular cells, which causes a destructive thyroiditis.

- Amiodarone and its metabolite, desethylamiodarone, can act as a competitive antagonist of T3 on cardiomyocytes.

Amiodarone properties

A. Antiadrenergic properties

1. Alpha-blocking (vasodilation)

2. Beta-blocking (bradycardia)

B. Cytotoxic effects by

1. Lysis

2. Oxidative stress

3. Antigen release

C. Immunomodulatory properties

1. Emergence of sensibilized lymphocyte subsets
Table 5 Amiodarone-induced thyroid dysfunction:

classification, pathophysiology and management.

A. Amiodarone-induced hypothyroidism (AlH)

Characteristics

- Affects $4-22 \%$ of the treated population.

- The most likely mechanisms of AlH are an enhanced susceptibility to the inhibitory effect of iodine on thyroid hormone synthesis and the inability of the thyroid gland to escape from the Wolff-Chaikoff effect after an iodine load in patients with preexisting Hashimoto thyroiditis. In addition, iodine-induced damage to the thyroid follicles may accelerate the natural trend of Hashimoto thyroiditis toward hypothyroidism.

- Patients without underlying thyroid abnormalities are postulated to have subtle defects in iodine organification that lead to decreased thyroid hormone synthesis, peripheral downregulation of thyroid hormone receptors and subsequent hypothyroidism.

Management

LT-4 therapy, with gradual introduction. It improves quality of life and regulates lipid levels. Thyroid panel monitoring is strongly advised.

B. Amiodarone-induced thyrotoxicosis (AIT)

Characteristics

Type 1: usually affects patients with latent or preexisting thyroid disorders and is more common in areas of low iodine intake. It is caused by iodine-induced excess thyroid hormone synthesis and release (JodBasedow phenomenon).

Type 2: occurs in patients with a previously normal thyroid gland and is caused by a destructive thyroiditis that leads to the release of preformed thyroid hormones from the damaged thyroid follicular cells. Mixed forms of AIT may occur in an abnormal thyroid gland, with features of destructive processes and iodine excess.

Management

Depends on the type of AIT. Type 1 AIT is treated with high doses of antithyroid drugs to block thyroid hormone synthesis, while type 2 AIT is treated with a relatively long course of glucocorticoids. When the mechanism of hyperthyroidism is uncertain, a combination of glucocorticoids and thionamides is used as initial therapy. Thyroid panel monitoring is strongly advised.

interest that herbal medicine such as St John's wort can also activate PXR (103).

\section{Antiretroviral therapy}

Antiretroviral therapy (ART) is mainly responsible for the alterations in vitamin $\mathrm{D}$ metabolism, acting as PXR ligands, although there are slight differences in their mode of action. They induce cytochrome P450 altering thus the activity of several enzymes in this family. These include CYP24A1 which acts mainly at the liver and converts both $25(\mathrm{OH}) \mathrm{D}$ and its active form calcitriol $\left(1,25(\mathrm{OH})_{2} \mathrm{D}\right)$, to their inactive metabolites. They can also

https://eje.bioscientifica.com 
induce other cytochrome P450 enzymes involved in the biotransformation of active substances (e.g. CYP3A4).

Additionally to the aforementioned mechanisms, protease inhibitors (PIs), have been shown to suppress CYP2R1 and CYP27B (encoding for 25-hydroxylase and 1-a-hydroxylase respectively) in a dose-dependent manner, resulting thus in a decrease of $1,25(\mathrm{OH})_{2} \mathrm{D}$ levels (104, 105). Efavirenz (EFV), a non-nucleoside reverse transcriptase inhibitor (NNRTI), is the antiretroviral drug most involved in lowering vitamin D levels.

Cross-sectional and longitudinal studies have showed that efavirenz is associated with low $25(\mathrm{OH}) \mathrm{D}$ levels $(106,107,108)$. Nylen et al. showed that the prevalence of vitamin D deficiency $(<10 \mathrm{ng} / \mathrm{mL})$ increased from 27 to $43 \%$ at 48 weeks in patients initiating EFV-based ART (108). Apart from efavirenz, another ART regimen, zidovudine, a nucleotide reverse transcriptase inhibitor (NRTI), was associated with vitamin D deficiency, as MONET trial showed (109). In the same study, participants who changed from efavirenz or zidovudine to regiment with boosted PI (darunavir) achieved the greatest increase in vitamin D levels (109).

According to the latest version of the European AIDS Clinical Society Guidelines, vitamin D screening in patients receiving ARTs associated with low vitamin D levels is recommended (110). Recent studies in participants receiving EFV or TDF-cART showed that a dosage supplement of 50,000-60,000 IU per month was enough to reach the goal of $25(\mathrm{OH}) \mathrm{D} \geq 30 \mathrm{ng} / \mathrm{mL}$ after 6 months $(111,112)$.

\section{Antiepileptic drugs}

Among the conventional AEDs, early reports have focused on inducers of cytochrome P450 (CYP) enzyme such as carbamazepine, phenobarbital, phenytoin and primidone that can activate the PXR, increasing vitamin D metabolism and eventually leading to hypocalcemia and secondary hyperparathyroidism (113). In a total of 600 patients receiving AEDs, 45\% had 25(OH)D level $<20 \mathrm{ng} / \mathrm{mL}$ while deficiency was present in $54 \%$ of enzyme-inducing and $37 \%$ of non-enzyme-inducing antiepileptic drug groups (114). Interestingly, Tombini et al. found that patients taking multiple AEDs had lower levels of $25(\mathrm{OH}) \mathrm{D}$ than patients taking single therapy, with 25(OH)D levels depending on treatment duration (115).

To date, there is lack of robust clinical studies to evaluate the effects of conventional and newer AEDs on vitamin D levels, in order to suggest the appropriate use of vitamin D supplementation. According to the Endocrine Society Clinical Practice Guideline, patients on medications affecting vitamin $\mathrm{D}$ metabolism are suggested to receive a higher dose (two to three times higher; at least 6000-10,000 IU/day) of vitamin D to treat vitamin D deficiency to maintain a $25(\mathrm{OH}) \mathrm{D}$ level above $30 \mathrm{ng} / \mathrm{mL}$, followed by maintenance therapy of 3000-6000IU/day (116).

\section{Antiresorptive drugs for osteoporosis and hypocalcemia}

The risk of symptomatic hypocalcemia in patients with osteoporosis receiving antiresorptive drugs is small. Case reports and retrospective analyses have identified a number of risk factors associated with the development of hypocalcemia in those receiving inhibitors of bone resorption; these include malnutrition, malabsorption, renal insufficiency, hypomagnesemia, vitamin D deficiency and bone metastasis usually treated with higher dosage of bisphosphonates and denosumab (117).

Body et al. reported that the type of cancer (with smallcell lung cancer and prostate being the most common), creatinine clearance $<60 \mathrm{~mL} / \mathrm{min}$, higher alkaline phosphatase levels, emerge as factors that are significantly associated with the risk of developing hypocalcemia among denosumab-treated patients participating in three identically designed phase 3 trials of denosumab $120 \mathrm{mg}$ s.c. (118). Moreover, hypocalcemia occurs more frequently in patients receiving denosumab than in those receiving zoledronic acid and during the initial stages of therapy, but 'stabilizes' thereafter, irrespective of the duration of exposure (119).

\section{Calcimimetics}

Cinacalcet is a known allosteric activator of the calciumsensing receptor which can decrease parathyroid hormone (PTH) secretion by the parathyroid glands.

A recent meta-analysis of 24 RCTs (including 10,031 dialysis patients) confirmed the significant higher risk of hypocalcemia (120). Moreover, a post hoc analysis of the randomized, double-blind, placebo-controlled EValuation Of Cinacalcet Hydrochloride Therapy to Lower CardioVascular Events (EVOLVE) trial showed an increased incidence of at least one episode of hypocalcemia developed within 16 weeks after the first administered dose in patients randomized to cinacalcet compared to those randomized to placebo (58.3 vs $14.9 \%$, respectively) (121). 


\section{Glucocorticoids}

It is well known that glucocorticoids reduce $1,25-(\mathrm{OH})_{2} \mathrm{D}_{3}$ levels via disturbing its biosynthetic and catabolic enzymes. In particular, glucocorticoids decrease the CYP27B1, while enhance the expressions of CYP3A1, CYP24A1 the dominant enzymes for vitamin $\mathrm{D}$ degeneration, resulting in vitamin $\mathrm{D}$ depletion and consequently in reduced intestinal calcium absorption. Moreover, independently of $1,25(\mathrm{OH})_{2} \mathrm{D}_{3}$, glucocorticoids can decrease the transcellular pathway of intestinal absorption via reducing duodenal transient receptor potential vanilloid subfamily member 6 (TRPV6), Calbindin-9k (CB9k) and plasma membrane calcium ATPase 1b (PMCA1b) expression (122). According to the Endocrine Society Clinical Practice Guideline, glucocorticoids are included in the medications affecting vitamin D metabolism, thereby patients taking glucocorticoids are suggested to receive a higher dose (two to three times higher) to maintain vitamin D sufficiency (116).

\section{Antineoplastic drugs}

Rare cases of hypocalcemia due to drug-induced either reversible/functional or irreversible hypoparathyroidism include novel drugs such as immune check point inhibitors (123) antineoplastic drugs (adriamycin, doxorubicin, cytarabin, vinblastin) (124).

\section{Medication-induced osteoporosis: When to screen and treat}

Most harm concerning bone health is done by glucocorticoids, aromatase inhibitors and androgen deprivation treatment by GnRH agonists (125) (Table 6).

\section{Glucocorticoid-induced osteoporosis (GIO)}

Significant bone loss starts immediately after introducing glucocorticoid (GC) therapy. Skeletal fractures may occur within 3-6 months of starting GCs, and up to 30-50\% of patients on long-term GC treatment will suffer an osteoporotic fracture $(126,127)$. Both high daily and high cumulative GC doses increase the risk of fracture, particularly vertebral fracture, due to the greater effects of GCs on trabecular bone than on cortical bone (128). Daily prednisolone doses of $7.5 \mathrm{mg}$ or higher (or equivalent doses of other GCs) are associated with the greatest risk. However, a significantly increased fracture risk was seen even in patients with median prednisolone doses as low as $2.5 \mathrm{mg}$ daily. Decreased bone mass and increased fracture risk has also been demonstrated with inhaled and alternate day treatment regimens with GCs (128).

GCs adversely affect all phases of bone remodeling. Bone resorption is initially increased through various mechanisms, including decreased production of osteoprotegerin, an endogenous inhibitor of bone resorption, increased formation of RANK ligand that stimulates osteoclastogenesis and an increase in osteoclast survival. GCs also promote apoptosis of osteocytes, the mechanosensors that normally maintain bone strength by coordinating bone remodeling. Finally, as skeletal exposure to GCs continues, bone formation is suppressed by apoptosis of existing osteoblasts and decreased recruitment of new osteoblasts and a state of decreased bone remodeling ensues long term (126).

As GCs rapidly increase fracture risk, it is important to identify patients at moderate and high risk who would benefit from appropriate preventative treatment, soon after introducing GCs, during the first 6 months latest (128).

All guidelines recommend that patients treated with GCs for $\geq 3$ months should have an optimized intake of calcium and vitamin $\mathrm{D}$, together with appropriate lifestyle modifications, such as a well-balanced diet, regular weight-bearing physical activity and avoidance of alcohol and smoking. Patients with moderate and high fracture risk should receive an oral bisphosphonate. If this treatment is inappropriate, an intravenous bisphosphonate

Table 6 List of drugs inducing bone loss. Adapted from Mirza and Canalis (125)

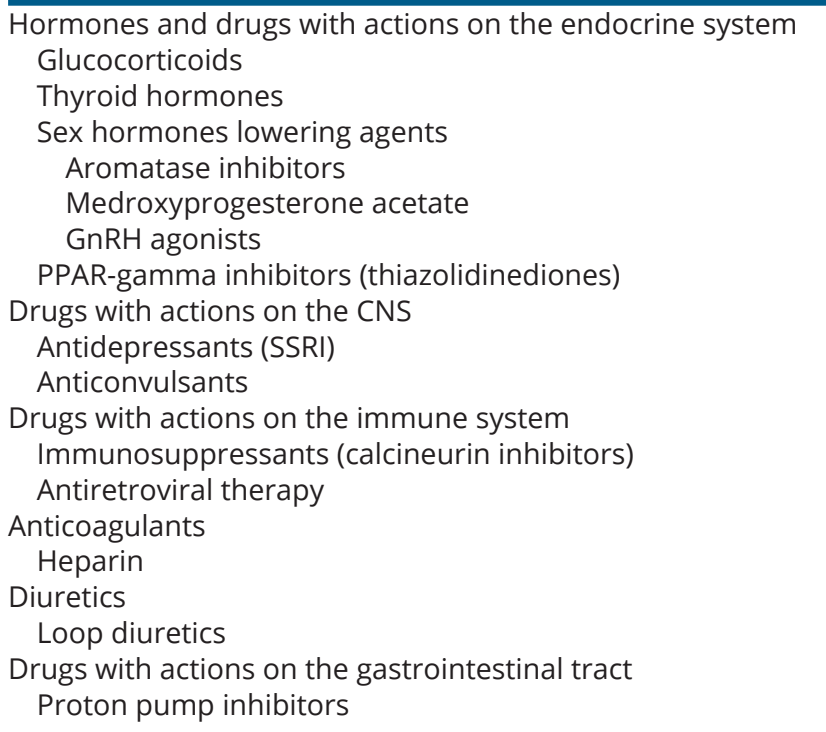

$\mathrm{GnRH}$, gonadotropin-releasing hormone; PPAR-gamma, peroxisome proliferator-activated receptor gamma; SSRI, selective serotonin reuptake inhibitors. 
formulation should be considered, and teriparatide if a bisphosphonate is not appropriate. Bisphosphonates are the most commonly used treatment for GIO and are generally well tolerated. The medication doses equal those used in postmenopausal osteoporosis. As the main long-lasting pathogenetic mechanism in GIO is reduced bone formation, in patients with very high fracture risk or prevalent fractures teriparatide therapy stimulating bone formation should be introduced. Teriparatide has been shown to produce superior BMD increases compared to oral bisphosphonates (129). GC treatment is a potentially reversible risk factor for osteoporosis; when GC treatment is terminated, BMD increases and fracture risk declines (127, 128, 130). Pharmacological anti-osteoporotic therapy could be stopped upon withdrawal of GC unless the patient remains at increased risk of fracture.

\section{Aromatase inhibitors in women with breast cancer and bone loss}

Aromatase inhibitors (AIs) lower aromatase activity and reduce estrogen levels by 98\% (131). As oestrogens play a crucial role in bone tissue homeostasis (132) reducing oestrogens adversely affects bone quantity and quality. In contrast to GCs, AIs predominantly affect cortical bone that composes $80 \%$ of bone tissue and mostly determines bone strength. AI-associated bone loss (AIBL) leads to a marked increase of bone resorption, with a 2to 4-fold increased bone loss compared to physiologic postmenopausal BMD loss (133). Fractures occur at younger ages and higher BMD than expected for patients in this age group without breast cancer. Even hip fracture incidence is higher and occurs earlier in postmenopausal women on AIs (134).

It is recommended that all women starting adjuvant therapy with AIs should be carefully assessed for baseline risk of osteoporotic fractures (DXA measurement; clinical risk factors) $(135,136)$. All patients initiating or receiving AI therapy with any two of the following risk factors should receive antiresorptive therapy: T-score $<-1.5$, age $>65$ years, low BMI $\left(<20 \mathrm{~kg} / \mathrm{m}^{2}\right)$, family history of hip fracture, personal history of fragility fracture after age 50 years, oral corticosteroid use of $>6$ months and current or history of smoking (135).

Several antiresorptive agents can prevent and treat AIBL including oral and i.v. bisphosphonates. Overall, the evidence for fracture prevention is strongest for denosumab $60 \mathrm{mg}$ s.c. every 6 months $(135,137)$. Additionally, recent studies as well as an individual patient data meta-analysis of all available randomized trial data support additional anticancer benefits from adjuvant bisphosphonate treatment in postmenopausal women with a 34\% relative risk reduction in bone metastasis and 17\% relative risk decrease in breast cancer mortality that needs to be taken into account when advising on management of AIBL (138).

\section{Androgen deprivation therapy in patients with prostate cancer and bone loss}

Androgen deprivation therapy (ADT) dramatically reduces testosterone and oestrogen concentrations, induces a high bone turnover with rapid bone loss similar to that in early menopause and results in an increased risk of fracture (139).

The extent of bone loss observed under ADT for prostate cancer in men receiving GnRH analogs is 4\% BMD loss per year (140). Patients with untreated prostate cancer already have a high prevalence of osteoporosis (4-38\%) (141). This increases to $53 \%$ in patients with prostate cancer receiving ADT (142). In a large meta-analysis of 14 trials, men who had ADT had an increased risk of overall fracture of $23 \%$ compared with men with prostate cancer who did not receive ADT (143). The fracture risk is directly correlated with the number of GnRH agonist doses given (144).

Before introducing ADT, men should be assessed for $\mathrm{BMD}$, fracture risk by FRAX ${ }^{\circledR}$ tool and other secondary causes of osteoporosis. An initial low BMD (T-score $<-2.5$ or $<-1$, with other risk factors) indicates a high risk of subsequent nonmetastatic fracture. General measures for bone health should be followed. Bisphosphonates have all been shown to prevent loss of BMD in patients with prostate cancer (145). Of antiresorptive medications, 6-12 monthly zoledronic acid and 6-monthly denosumab are considered the most convenient and reliable treatments. In a placebo-controlled trial of denosumab in 1468 men receiving $\mathrm{ADT}$ for nonmetastatic prostate cancer, 36 months of denosumab treatment was associated with a $62 \%$ relative reduction in new vertebral fractures $(1.5 \%$ with denosumab versus $3.9 \%$ with placebo) (146).

\section{Drug-induced diabetes, obesity and its metabolic complications}

\section{Drug-induced obesity and its metabolic consequences: focus on mechanisms and possible therapeutic options}

Modern pharmacological treatments for various medical conditions like diabetes, mental health disorders and cardiovascular disease can contribute to weight gain both 
in patients with and without this predisposition. It is vital that this is recognized by the medical community so that healthcare professionals warn the patient of this potential side effect.

\section{Glucose-lowering medications}

Insulin is very effective in controlling glycaemia rapidly but is also well recognized in inducing a mean of approximately $4 \mathrm{~kg}$ weight gain in a dose-dependent manner (147). This takes place during the first year of treatment and then tends to plateau unless further increases in dose are made. Long-acting insulin use alone tends to be more weight friendly than basal bolus regimens and there is some evidence that specific types of long-acting insulins may be better than others in this respect (e.g. detemir) (148). The mechanism appears to be multifactorial and includes the stimulation of hunger, the 'retention' of calories, the anabolic effects of insulin as well as snacking in order to prevent or treat hypoglycemia. Sulphonylureas and meglitinides appear to be working in similar ways, while in the thiazolidinediones group, the weight gain is via fluid retention and increase of subcutaneous fat, being dose dependent, ranging from 2 to $4 \mathrm{~kg}$ (149).

\section{Psychotropic medication}

Psychotropic medication may be effective for the treatment of the underlying psychopathology but can have deleterious effects on metabolic control. The weight gain happens rapidly, and a 5\% increase of body weight within the first 4 weeks of initiation is a poor prognostic sign. Patients on psychotropic medication tend to overeat but also have a preference for energy-dense foods (150). The medications interfere with central neurotransmission of dopamine, serotonin, histamine and endocannabinoids in selective and non-selective ways making it challenging to be certain about the precise mechanism underlying weight gain. Antidepressants of the tricyclic/ tetracyclic class e.g. amitriptyline, mirtazapine tend to induce more weight gain than selective serotonin reuptake inhibitors e.g. fluoxetine and citalopram (151). Antipsychotics are the most potent weight inducers among the class of psychotropic medications with patients often exceeding their ideal body weight by 20\% (152).

\section{Epilepsy medications}

Drugs for epilepsy are also associated with weight gain due to their interference with central neurotransmitters and cytokines. Valproate, carbamazepine, pregabalin and gabapentin tend to cause more weight gain than lamotrigine and levetiracetam, while agents like topiramate are associated with weight loss (153).

\section{Glucocorticoids}

GCs, almost invariably associated with weight gain and possibly metabolic complications (154), also induce hepatic and peripheral insulin resistance, often resulting in the metabolic syndrome and diabetes (155).

\section{Principles of treatment}

By far the most effective treatment is discontinuation of the therapy, but this can be challenging specifically in patients who have benefited from the drug and their disease stability. If this is not feasible, then the standard principles of weight loss apply. Indeed, these could be introduced upon initiation of the relevant medication. Lifestyle modification should be performed in a supportive way, and one should consider the strong biological triggers of the weight gain. Obesity pharmacotherapy should be considered in all cases. The use of GLP-1 analogs is probably the safest option for the majority of patients and has been applied successfully in patients with mental health disorders as part of a randomized controlled trial (156). The use of centrally acting non-hormonal treatments e.g. bupropion/naltrexone, topiramate/phentermine and lorcaserin should be considered, but with caution and frequent monitoring especially in patients with mental health disease. Obesity surgery is by far the most effective treatment both for weight loss and metabolic control (157). It should certainly be considered in all patients and even those with severe mental illness as long as this is stable and there is appropriate psychological support available.

\section{Antipsychotic drugs induced diabetes (SGAs)}

In patients with preexisting diabetes, the initiation of antipsychotic drugs (SGAs) has been associated with worsening hyperglycemia (158), and in non-diabetics with weight gain, obesity, hypertriglyceridemia $(159,160$, 161). A prospective randomized study, CATIE, showed that chronic treatment with different antipsychotic agents was associated with differential weight gain and changes in glucose levels (162) (Table 7). Nicol et al. (163) used gold-standard measures of adiposity (dualenergy X-ray absorptiometry and MRI) and insulin 
Table 7 Weight and HbAIC changes, during treatment with antipsychotic agents (Lieberman et al. (162)).

\begin{tabular}{|c|c|c|}
\hline Antipsychotics & Change in HbAIC (\%) & $\begin{array}{l}\text { Change in weight } \\
\text { (lb) }\end{array}$ \\
\hline Olanzapine & $0.40 \pm 0.07$ & $9.4 \pm 0.9$ \\
\hline Quetiapine & $0.04 \pm 0.08$ & $1.1 \pm 0.9$ \\
\hline Risperidone & $0.07 \pm 0.08$ & $0.8 \pm 0.9$ \\
\hline Ziprasidone & $0.11 \pm 0.09$ & $-1.6 \pm 1.1$ \\
\hline Perphenazine & $0.09 \pm 0.09$ & $-2.01 \pm 1.1$ \\
\hline
\end{tabular}

sensitivity (a hyperinsulineric-englycemic clamp) and found that 12 weeks of treatment with low-dose olanzapine, risperidone or aripiprazole in youths who were antipsychotic-naïve, produced rapid-onset adverse changes in adiposity and insulin, with larger increases in those who used olanzapine compared with those that used risperidone and aripiprazole.

Other proposed mechanisms may be more relevant to mechanisms underlying treatment-related ketoacidosis. Blockade of pancreatic beta-cell 5HT-1A receptors might contribute to hyperglycemia and pancreatitis reported with SGAs $(164,165)$. Alpha 2 adrenergic inhibition of insulin release has also been suggested as a possible mechanism of antipsychotic-induced hyperglycemia (166).

Tricyclic antidepressants (TCAs) have been associated with weight gain and worsening glycemia in diabetic patients (167). However, SSRIs and other antidepressants are largely weight neutral; some have been associated with weight loss and improved insulin sensitivity (168). The effect of SSRIs upon weight depends upon the specific medication prescribed and the length of treatment.

In addition, weight gain during SSRI treatment is significantly related to poor appetite at the beginning of treatment (169). Until the exact mechanisms are elucidated, it is prudent to screen for diabetes at baseline and monitor blood glucose levels at reasonable intervals during treatment with all antidepressants (170).

\section{New insights in steroid diabetes}

Hyperglycemia is one of the most important adverse effects of glucocorticoid administration (171, 172). Real estimations of the risk for steroid-induced hyperglycemia (SIH) and diabetes (SIDM) are quite difficult, as steroid formulations, treatment duration, dosing regiments and individual susceptibility may vary greatly. A large recent meta-analysis of 13 studies has shown the overall event rate of hyperglycemia and diabetes among patients treated with GCs was 32.3 and $18.6 \%$, respectively (173). Moreover, GCs approximately double the risk of developing diabetes in patients without a prior history of hyperglycemia (174).

The mechanism by which GCs cause diabetes predominantly involves insulin resistance, but $\beta$-cell function and insulin secretion are also impaired particularly at higher doses (175). Thus, GCs increase hepatic gluconeogenesis and glucose output, while they also inhibit glucose uptake in muscle and adipose tissue, primarily by inhibiting glucose transporter type 4. During chronic therapy, promotion of weight gain and visceral fat expansion may further contribute to their diabetogenic effects.

The initial steps to prevent development of postprandial hyperglycemia and improve glycemic control should provide dietary counseling for restriction of carbohydrates and advice for increased physical activity. Especially for temporary steroid therapy in patients without a history of diabetes or with adequately controlled diabetes, diet and lifestyle may be sufficient to achieve therapeutic goals. In the more severe cases, choice of therapy should take into account pharmacokinetics and pharmacodynamics of the used steroid compounds, as well as preexisting glycemic status and the presence of comorbidities.

In the cases where glycemia is relatively mild $(<200 \mathrm{mg} / \mathrm{dL})$, together with or after lifestyle measures, hypoglycemic drugs with insulin sensitizing actions are indicated as the first choice $(172,175)$. Metformin can represent an attractive option given acceptable liver and renal function, because it directly counteracts glucocorticoid effects by enhancing insulin sensitivity and reducing gluconeogenesis. Thiazolidinediones (TZDs) may also improve glycemia by antagonizing the pathways of steroid-induced insulin resistance and by neutralizing their adverse effects on $\beta$-cell function. Their usefulness, however, is limited because of the risk of edema and bone fractures, which they share with GCs $(175,176)$. Second choice drugs or insulin therapy can be considered, taking into account their profile of action, tolerance, cost, and risk of hypoglycemia.

Basal insulin should be used with high doses of glucocorticoids, mainly in patients with existing diabetes, with a starting dose of $0.1 \mathrm{U} / \mathrm{kg}$ before bedtime (177). Another possibility, especially for those receiving a single morning steroid dose, is to opt for basal insulin in the morning in order to blunt the late afternoon peak of intermediate-acting GCs. In case of multiple steroid doses or longer-acting GCs (dexamethasone), basal insulin should be reduced to $30 \%$ of daily insulin requirements with the remaining $70 \%$ divided between meals $(177,178)$. 
Conclusively, is clear that guidelines for the management of SIDM and SIH (179) should be developed and universally shared in order to harmonize the treatment of these conditions overtaking empirical therapeutic strategies.

\section{Hyperglycemia and diabetes secondary to treatment with commonly used drugs}

Apart from corticosteroids and antipsychotics, there is a broad spectrum of commonly prescribed drugs that can potentially have an effect on glucose metabolism. Diuretics and beta-blockers have been historically implicated with drug-induced hyperglycemia. Specifically, long-term use of beta-blockers or thiazide diuretics increased new onset diabetes with a relative risk of 1.20-1.32 in prospective cohorts (180). Another drug class, commonly used in patients with cardiovascular disease that may also have diabetogenic potential, is statins. Statins interfere with many glucoregulatory pathways resulting in decreased insulin secretion and action, with diabetes risk being associated with dose and duration of their use and other diabetes risk factors (181).

Somatostatin analogs (SA), primarily used for acromegaly and Cushing's disease by endocrinologists, are characterized by an increased risk for developing diabetes, via inhibiting insulin and glucagon secretion. Particularly, pasireotide, the newer and more potent SA, almost tripled new onset diabetes and has been associated with hyperglycemia and diabetes in up to $30 \%$ of patients, compared to octreotide or lanreotide (182). Finally, the anticancer agents, mechanistic target of rapamycin (mTOR) inhibitors, temsirolimus and everolimus, have been associated with $5.3 \%$ incidence of high grade hyperglycemia (blood sugars $>250 \mathrm{mg} / \mathrm{dL}$ ) (183).

In all the above drug classes, surveillance for diabetes is recommended and once noted, lifestyle modification and/or antidiabetic medications are recommended for treatment. In the majority of patients, hyperglycemia is mild and usually reversible upon discontinuation of the responsible agent. However, the benefit of continuing the drug often outweighs the risk of discontinuation, particularly if hyperglycemia can be treatable (184).

\section{Drug-induced dyslipidemias associated with endocrinopathies}

Several drugs can affect either positively or negatively principal lipoproteins. The ones most commonly used affecting lipoprotein profile are steroid hormone-based drugs and antidiabetic medications.

\section{Steroid hormones based drugs}

Estrogens Estrogen administration raises high-density lipoprotein cholesterol (HDLc) levels by 5-20\% (particularly the $\mathrm{HDL}_{2}$ cardioprotective subfraction) and lowers, in a dose-dependent manner, total cholesterol (TC) and low-density lipoprotein cholesterol (LDLc) by 2-10\% and by $5-20 \%$ respectively (185). These estrogenic effects are due in part to the induction in LDL receptors, the increase in apolipoprotein $\left(\operatorname{apoA}_{1}\right)$ production and the decrease in apolipoprotein B (apoB) levels. Additionally, a decrease in lipoprotein (a) $[\mathrm{Lp}(\mathrm{a})]$ concentration, which is an independent cardiovascular risk factor, by $20-25 \%$ has also been observed $(185,186)$. However, estrogens can also increase triglyceride (TG) levels by 30-40\% mainly in patients with genetic background of hypertriglyceridemia and this can lead to gross hyperchylomicronemia and risk of acute pancreatitis. The increase in TG levels arises from the hepatic overproduction of very low-density lipoproteins (VLDL) by oral estrogens as well as by the reduced lipoprotein lipase (LPL) and hepatic lipase (HL) activities resulting in a reduction of TG clearance $(185,187)$. Several factors can modulate estrogenic effects on lipid profile such as route of administration, type of preparations, dosing regimen, genetic background and baseline lipid abnormalities (185).

Progestogens The effect of progestogens on lipid metabolism is complex. In general they antagonize the estrogeninduced lipid changes, raising LDLc and decreasing, sometimes intensely, HDLc levels by $15-30 \%$ (188). The decline in HDLc is due to increased catabolism of this particle induced principally by an increase in HL lipase activity. These effects depend on the androgenic potency of each molecule. Progestogens with strong 'androgenicity' such as norethisterone, norgestrel and levonorgestrel can reduce HDLc levels as low as $10 \mathrm{mg} / \mathrm{dL}$. Less androgenic progestogens like desogestrel and natural progesterone induce milder lipid changes. The third-generation compounds (desogestrel, gestodene) are less androgenic and have neutral or even favorable effects on LDLc and HDLc levels but may cause hypertriglyceridemia $(185,187)$.

Estrogens and progestogens are used frequently in combined preparations for oral contraception or menopausal hormone therapy (HRT). In general, when combining both steroids, the estrogen-induced HDLc elevation is blunted but the reduction in LDLc is not affected (185). Triglycerides, however, should be measured and taken into account before considering any hormonal therapy containing estrogens (187). 
Androgens Androgen replacement therapy with testosterone in early clinical studies showed small decreases in TC and LDLc levels and more profound decrease in HDLc concentrations (189), although more recent meta-analyses find no changes or small reduction in TC and TG levels and no change in HDLc (190). Interestingly, transdermal testosterone regimen has less influence on HDLc levels than intramuscular administration or oral preparations. Mechanisms for the decrease in HDL concentrations include increases of the scavenger receptor class B type I (SRBI) in the liver and increase in HL activity. Studies of the testosterone treatment impact on $\mathrm{CV}$ disease and atherosclerosis have shown conflicting results with some studies reporting an increased risk and others no risk $(191,192)$.

Corticosteroids In the Third National Health and Nutrition Examination Survey (NHANES) with 15.000 subjects over age 60 years, oral and inhaled GCs were associated with higher HDLc and $\mathrm{ApoA}_{1}$ levels without adverse LDL or TG profile (193). It seems that these drugs sometimes increase TC (+10-15\%), more often TG (until $+40 \%)$, but more constantly increase HDL levels up to $20-40 \%$. The dose of GCs, sex, duration of treatment, route of administration, preexisting obesity or metabolic syndrome are important modulating variables.

\section{Antidiabetic drugs}

DPP-4 inhibitors The DPP-4 inhibitors exert direct hypolipidemic properties. In short-term studies with sitagliptin, vildagliptin and alogliptin a decrease in postprandial chylomicron TG and apoB48 it was shown, while the effect on fasting TG was less notable (194).

GLP-1 receptor agonists Most studies investigating the impact on lipid profile were performed with either liraglutide or exenatide in healthy subjects and in patients with T2DM and showed significant reduction of fasting and postprandial chylomicron TG levels, modest decreases in TC and LDLc and small or no significant change in HDLc levels (195). In the case of liraglutide, it seems that there is direct effect of the drug on the expression of genes involved in the biosynthesis of chylomicron and a reduction of APOB48 pool $(194,196)$.

SGLT-2 inhibitors Concerning lipid profile, these agents mediate small increase in HDLc, decrease or have no effect on TG and increase LDLc levels from 3 to $8 \%$ $(187,197)$. While the favorable effects observed in HDLc and TG concentrations could be explained by body weight reduction, the mechanism behind the small increase in LDLc remains unclear. One explanation could be that these drugs cause a switch from carbohydrate to lipid utilization, thereby increasing hepatic fatty acids levels to induce ketone and hepatic TC production. Empagliflozin was also associated to a lower LDL receptor expression and LDLc catabolism (198).

Drug-induced effects on serum lipid levels and CV risk are summarized in Table 8.

\section{Drug-induced adrenal dysfunction}

\section{Glucocorticoid-induced adrenal suppression and Cushing syndrome: A delicate balance}

GCs when administered exogenously to suppress adrenal function, as in the case of congenital adrenal hyperplasia (CAH), can inhibit HPA axis activity and lead to suppression of adrenocortical glucocorticoids and androgens secretion. In $\mathrm{CAH}$, their administration aims to replace the lack of endogenous cortisol and prevent the consequences of androgen excess, while

Table 8 Effect of endocrine-based drugs on serum lipid levels and CV risk.

\begin{tabular}{l}
\hline Drug \\
\hline Steroid hormone \\
Estrogen \\
Progestogen \\
Androgen \\
Corticosteroids \\
Antidiabetic drug \\
DPP-4 inhibitor \\
GLP-1R agonist \\
SGLT-2 inhibitor
\end{tabular}

\begin{tabular}{|c|c|}
\hline TC & LDLC \\
\hline$\downarrow$ & $\downarrow$ \\
\hline$\leftrightarrow$ or $\uparrow$ & $\leftrightarrow$ or $\uparrow$ \\
\hline$\leftrightarrow$ or $\downarrow$ & $\leftrightarrow$ or $\downarrow$ \\
\hline$\leftrightarrow$ or $\uparrow$ & $\leftrightarrow$ or $\uparrow$ \\
\hline$\leftrightarrow$ & $\leftrightarrow$ \\
\hline$\downarrow$ & $\downarrow$ \\
\hline$\leftrightarrow$ or $\uparrow$ & $\uparrow$ \\
\hline
\end{tabular}

\begin{tabular}{|c|}
\hline TG \\
\hline$\uparrow$ or $\uparrow \uparrow$ \\
\hline$\leftrightarrow$ or $\downarrow$ \\
\hline$\leftrightarrow$ or $\downarrow$ \\
\hline$\uparrow$ \\
\hline$\downarrow$ (pp) \\
\hline$\downarrow$ \\
\hline$\downarrow$ \\
\hline
\end{tabular}

\begin{tabular}{|c|}
\hline HDLC \\
\hline$\uparrow$ \\
\hline$\downarrow$ \\
\hline$\downarrow$ \\
\hline$\uparrow$ \\
\hline$\leftrightarrow$ \\
\hline$\leftrightarrow$ or $\uparrow$ \\
\hline$\uparrow$ \\
\hline
\end{tabular}

\begin{tabular}{c}
\hline $\mathbf{L p}(\mathrm{a})$ \\
\hline \\
$\downarrow$ \\
$\leftrightarrow$ or $\downarrow$ \\
$\downarrow$ \\
$\mathrm{NA} / \mathrm{I}$ \\
$\mathrm{NA} / \mathrm{I}$ \\
$\mathrm{NA} / \mathrm{I}$ \\
$\mathrm{NA} / \mathrm{I}$
\end{tabular}

CV risk
$\uparrow \leftrightarrow$ or $\downarrow$
$\leftrightarrow$ or $\uparrow$
$\leftrightarrow$ or $\uparrow$
NA/I

$\leftrightarrow$
$\downarrow$
$\downarrow$

$\uparrow$ increase, $\downarrow$ decrease, $\leftrightarrow$ no change, NA/I, data not available or insufficient, pp, post-prandial, TC, total cholesterol, LDLc, low-density lipoprotein cholesterol, HDLc, high-density lipoprotein cholesterol, TG, triglycerides, LP(a), lipoprotein(a), CV, cardiovascular, DPP-4, dipeptidyl peptidase-4, GLP-1R, glucagon like peptide-1 receptor, SGLT-2, sodium glucose co-transporter-2. 
avoiding glucocorticoid overtreatment and development of Cushing syndrome. Because this goal is not easily attainable, non-optimized treatment of $\mathrm{CAH}$ contributes to the poor health status of adults with CAH.

To control the overnight HPA-driven increase in adrenal androgens, a variety of glucocorticoid treatment regimens have been used (199). Regarding, biochemical monitoring, optimal treatment with glucocorticoids is achieved when serum levels of $17-\mathrm{OH}$ progesterone (17OHP) are found above normal range (between slightly above the upper limit and three times the upper limit of normal range). Circulating concentrations of androstenedione should be within normal range. Excess glucocorticoid exposure is suspected when $17 \mathrm{OHP}$ concentrations are within or below normal range and androstenedione concentrations are low. Patients receiving hydrocortisone during the day will inevitably demonstrate high concentrations of 17OHP before taking their morning hydrocortisone dose; then these concentrations fall after taking the treatment. By contrast, patients treated with a night-time dose of prednisolone or dexamethasone might have normal or low concentrations of androgens on waking. Good control is important for fertility. Hypertension is common, so mineralocorticoid replacement therapy should avoid suppressing plasma concentrations of renin below normal range (as evaluated by measurement of plasma rennin activity), and blood pressure should be monitored regularly in adults with CAH (200). Trying to normalize androgen concentrations can lead to overtreatment with deleterious outcomes (i.e. cushingoid appearance, psychological effects, short stature, obesity, hypertension, osteoporosis, muscle atrophy and myopathy, insulin resistance and adverse metabolic profile. Furthermore, glucocorticoid overtreatment inhibits GnRH secretion leading to hypogonadotropic hypogonadism (201).

Optimal management of adults with 21OHD is far from being achieved. These patients present with many unmet medical needs, and additional research in the natural history of the disease as well as optimal therapeutic interventions are urgently needed to improve outcomes.

\section{Adrenolytic agents induce adrenal suppression: an unavoidable necessity}

Several compounds, including ketoconazole, metyrapone, etomidate, and mitotane, have been commonly used in the therapeutic management of severe hypercortisolism for any etiology of endogenous Cushing's syndrome or control of excess steroid production in adrenocortical carcinoma. Acting via interfering with one or more of the enzymes in the steroidogenic pathway, they can cause subsequent decrease in cortisol secretion and adrenal insufficiency. Thus, adrenal function should be monitored closely to these patients, as hydrocortisone replacement may be mandatory $(202,203)$.

\section{Drug-induced phaeo crisis}

Phaeochromocytoma crisis is a life-threatening condition, characterized by hemodynamic instability induced by a surge of catecholamines, manifested with a complexity of symptoms. (204).

Crises can occur spontaneously or can be precipitated by exercise, abdominal palpation, urination or by drugs (205). However, apart from anesthesia and beta-blockers, which are the most known precipitating factors in acute pheochromocytoma crisis, there are also other medications, commonly used in clinical practice, able to trigger this life-threatening condition (Table 9) (205). For example, the gastroprokinetic agent metoclopramide, a worldwide medication used very often to treat nausea and vomiting, is known to stimulate catecholamine secretion from pheochromocytomas. The mechanism of metoclopramideevoked hypertensive crisis in these patients likely involves an increase in norepinephrine release via presynaptic D2 receptor blockade, an inhibition of the vasodilatory effect of dopamine leading to potentiation of the hypertensive action of norepinephrine and epinephrine, and a direct stimulatory effect of the drug on pheochromocytoma cells. However, recently it was shown that serotonin receptors are also involved. Metoclopramide is able to act as a partial agonist at the serotonin (5-HT4) receptor type 4 . Recently, Guillemot J. et al. have discovered that pheochromocytomas actually express functional 5-HT4 receptors that are responsible for the stimulatory action of metoclopramide on catecholamine- and granin-derived peptide secretion (206).

Interestingly, glucocorticoids are actively involved in catecholamine metabolism, production, and release not only in healthy adrenal medulla but also in pheochromocytoma cells (205). In fact, they can exert inducing effects in crucial catecholamine biosynthetic enzymes such as phenylethanolamine N-methyltransferase that converts norepinephrine to epinephrine tyrosine hydroxylase, a rate-limiting enzyme in catecholamine metabolism, and proopiomelanocortin, an ACTH precursor (207). While in normal medulla catecholamine production and release is not affected by glucocorticoid administration, the anatomical and functional alterations 
Table 9 Medications that are implicated in adverse reactions in patients with pheochromocytoma and that can precipitate a crisis (205).

\begin{tabular}{l} 
Type of medication \\
\hline Dopamine D2 receptor antagonists (including some antiemetic \\
agents and antipsychotics) \\
Beta-adrenergic receptor blockers \\
Sympathomimetics \\
Opioid analgesics \\
Norepinephrine reuptake inhibitors (including tricyclic \\
antidepressants) \\
Serotonin reuptake inhibitors (rarely reported) \\
Monoamine oxidase inhibitors \\
Corticosteroids \\
Peptides \\
Neuromuscular blocking agents
\end{tabular}

in pheochromocytomas may increase the susceptibility of chromaffin cells to glucocorticoids. Dexamethasone and betamethasone, which have high glucocorticoid potency and long duration of action, are more likely to induce a pheochromocytoma crisis.

Thus, in patients with adrenal incidentalomas, glucocorticoids should be avoided or administered cautiously especially if the suspicion for pheochromocytoma is high (208). However, if dexamethasone suppression test is considered necessary before ruling out pheochromocytoma, the endocrinologist should preferably proceed with the overnight dexamethasone suppression protocol, as no cases of pheochromocytoma crisis have been reported, as yet, with this dose (209).

\section{Drug-induced gonadal dysfunction}

\section{Drug-induced amenorrhea: Differential diagnosis and clinical workup}

During women's reproductive lives, from menarche to menopause, the HPG axis is active and functioning. Medications can have profound effects on all components of the HPG axis and the outflow tract

\section{Hypothalamic-pituitary axis}

Medications can affect this axis in one of three ways:

\section{Alter the production or action of GnRH:}

Opioids: Opioids decrease GnRH production and release and may cause amenorrhea in young women as outlined in the section on opioids.

\begin{tabular}{|c|}
\hline Drugs \\
\hline $\begin{array}{l}\text { Metoclopramide, sulpiride, amisulpride, tiapride, } \\
\text { chlorpromazine, prochlorperazine, droperidol }\end{array}$ \\
\hline Propranolol, sotalol, timolol, nadolol, labetalol \\
\hline $\begin{array}{l}\text { Ephedrine, pseudoephedrine, fenfluramine, methylphenidate, } \\
\text { phentermine, dexamfetamine }\end{array}$ \\
\hline Morphine, pethidine, tramadol \\
\hline Amitriptyline, imipramine \\
\hline Paroxetine, fluoxetine \\
\hline Tranylcypromine, moclobemide, phenelzine \\
\hline Dexamethasone, prednisone, hydrocortisone, betamethasone \\
\hline ACTH, glucagon \\
\hline Succinylcholine, tubocurarine, atracurium \\
\hline
\end{tabular}

Hypothalamic-pituitary-adrenal axis (HPA): There is cross-talk between the HPA axis and the HPG axis which promotes amenorrhea as the functional adaptation to stress (210). Corticotropin releasing hormone infusion in women decreases gonadotropins, an effect prevented by GnRH administration. In addition, women given supraphysiological doses of prednisolone have decreased LH response to GnRH, suggesting a pituitary effect (210).

GnRH agonists: As GnRH effect is short lived, GnRH long-acting agonists, such as leuprolide, were developed to prolong its effect. However, while these agonists stimulate LH release for 5-12 days, thereafter LH concentrations plummet and a hypogonadotropic state ensues in both men and women. This effect appears to relate to GnRH receptor downregulation. This 'medical hypophysectomy' (as regards gonadotropins) induced by GnRH agonists has proved useful in the treatment of central precocious puberty, endometriosis, hormone dependent cancers as well as in assisted reproduction to prevent premature $\mathrm{LH}$ surges during ovarian stimulation.

\section{Induce hyperprolactinemia:}

Discussed in the section on drug-induced hyperprolactinemia and categorized in Table 2. If the medication cannot be discontinued, for example in the case of antipsychotics, the medication can be changed to one that does not elevate prolactin, such as quetiapine, or aripiprazole, which has both dopamine agonistic and antagonistic properties, can be added. These changes can only be considered in conjunction with the treating psychiatrist. 
3. Induce pituitary inflammation causing hypophysitis:

Discussed in the section on hypophysitis. Amenorrhea may occur in young women.

Ovary

The effect of chemotherapeutic agents on the ovary can be profound. Most anticancer medications affect dividing cells, such as granulosa and theca cells. Thus many women of reproductive age develop amenorrhea during chemotherapy, with high FSH and LH and low estradiol but menstrual function may return months later. The effect of such drugs on the oocytes/primordial follicles is variable and agent dependent. In addition, as the number of primordial follicles decrease with age, the effect of these drugs is also age dependent. For example, $5 \mathrm{~g}$ of cumulative cyclophosphamide may cause permanent amenorrhea in a woman in her $40 \mathrm{~s}$ but $10 \mathrm{~g}$ or more are needed to do the same in younger women. Alkylating agents are the most damaging, affecting both resting (oocytes) and dividing cells. These include cyclophosphamide, chlorambucil, melphalan, procarbazine, dacarbazine and busulfan. Agents such as vinca alkaloids, antimetabolites, heavy metals and TKIs may also cause amenorrhea. These include vinblastine, cytosine arabinoside, cis-platinum and imatinib. Antimetabolites such as methotrexate, fluorouracil, 6-mercaptopurine and vincristine have a low probability of causing amenorrhea. Information is available for certain drug regimen: for example, MOPP (mechlorethamine, vincristine, procarbazine and prednisone) may lead to permanent ovarian failure in $12-46 \%$, whereas newer regimen such as ABVD (doxorubicin, bleomycin, vinblastine, dacarbazine) appear to have less toxicity. In a report of over 2000 childhood cancer survivors greater than 18 years of age, $8 \%$ had ovarian failure, versus $0.8 \%$ of siblings (211). Even in those whose menses return after chemotherapy, earlier menopause may be anticipated.

\section{Outflow tract}

Progestin-releasing intrauterine contraceptive devices and implants are often associated with amenorrhea, which for many women may be a desirable effect, lasting only during their use. However, the effect of intramuscular depot medroxyprogesterone acetate, given every 3 months, may last longer and $25 \%$ of women can remain amenorrheic up to a year after the last injection. This may relate to the accumulation of the drug within adipose tissue. If the drug cannot be discontinued, there is no suitable substitute or the drug has had a permanent effect, as in the use of chemotherapeutic agents, estradiol and progestin replacement must be given to hypoestrogenic women to preserve bone and cardiovascular health, if not contraindicated.

\section{Anabolic steroids on the reproductive system of females}

Anabolic-androgenic steroids (AASs), often shortened to 'anabolic steroids', are synthetic steroidal androgens, which promote the growth of skeletal muscle (anabolic effects) and the development of male sexual characteristics (androgenic effects) in both males and females (212). These compounds, which are structurally related to testosterone, exert their action by binding to androgen receptor and exhibit both masculinizing as well as anabolic effects to a varying degree.

Nowadays, AASs are the most widely misused appearance and performance drugs (APEDs) and their use has become a serious global public health problem. A variety of adverse effects of AASs use on several organ systems have been described, including cardiovascular, hematologic, psychiatric, hormonal and metabolic effects (213) (Table 10). In females, AASs use can be associated with menstrual irregularity and infertility due to a negative feedback in the regulation of the hypothalamic-pituitarygonadal axis, and subsequent suppression of pituitary LH and FSH secretion. It is known, however, that chronic strenuous exercise can often lead to the same symptoms due to disruption of the GnRH pulse generator, making it difficult to distinguish the effects of intensive exercise and AASs use (214). In females, anabolic steroids can also cause masculinization. Acne, hirsutism alopecia, mammary atrophy, clitoris hypertrophy and irreversible deepening of the voice are further consequences of AASs use. No welldocumented case reports or studies concerning possible irreversible clitoris hypertrophy as a result of AASs use in women are available (215). Finally, there seems to be no connection between the administration of AASs in young female athletes and breast cancer (215).

Animal studies in female rats and mice have collectively shown that administration of nandrolone decanoate, the most commonly used injectable steroid by athletes and non-athletes, not only results in decreased serum levels of $\mathrm{LH}, \mathrm{FSH}$, progesterone and estrogen due to an increase in circulating androgen levels, but also causes irreversible damage to the ovarian tissue (216). Previous studies described that both folliculogenesis and 
Table 10 Adverse effects of anabolic-androgenic steroids (AASs) use.

Cardiovascular system
Dyslipidemia
Atherosclerosis
Cardiomyopathy
Cardiac conduction abnormalities
Polycythemia
Hypertension
Endocrine (males)
HPT suppression
Gynecomastia
Hypogonadism
Prostatic hypertrophy/cancer
Endocrine (females)
HPO suppression
Mammary atrophy
Menstrual irregularities
Masculinization effects
Psychiatric
Mood disorders: mania/depression
Aggression
AAS dependence
Cognitive defects
Musculoskeletal
Premature epiphyseal closure (in adolescent)
Tendon rupture
Hepatic
Inflammatory and clolestatic effects
Peliosis hepatis
Neoplasms (rare)
Kidney
Renal failure secondary to rhabdomyolysis
Focal segmental glomerulosclerosis

Adopted from: Pope Jr et al. (213).

luteogenesis have been severely affected by nandrolone decanoate in a dose- and time-dependent manner, resulting in follicular apoptosis, ovarian degeneration and atrophy $(217,218)$.

Accumulating evidence shows that about 32\% of people who misuse AASs develop dependence syndrome via at least three separate pathways: the anabolic, androgenic and hedonic mechanisms (219, 220). Data show that anabolic steroid use in women is accompanied by extreme dissatisfaction with body image and a body dysmorphic syndrome analogous to anorexia (221). Symptoms of dependence can include tolerance or withdrawal once AASs use stops. Withdrawal symptoms can include fatigue, restlessness, loss of appetite, insomnia, reduced libido and the most dangerous of all, depression.

Although testing procedures are now in place to detect steroid use, novel compounds put athletes who use these substances, one step ahead of testing efforts. We can suspect AASs abuse in someone who exhibits a change in behavior, such as depression, irritability or aggression or in a woman who develops irregular menstrual cycles, hirsutism, acne, breast atrophy, temporal hair recession, deepening of the voice, clitoromegaly, increased muscle mass and decreased body fat. In blood tests, these patients usually develop high hematocrit, low-to undetectable LH levels and low SHBG levels. The approach to the patient taking exogenous AASs is really challenging as individuals are very reluctant to discuss this with their physicians, with one study reporting that $56 \%$ of users had never told their physicians about their use (222).

Special attention should also be paid on 'dietary/ nutritional supplements' that are claimed to be 'thermogenic', 'non-anabolic', 'non-androgenic' supplements, such as vitamins, minerals, herbs, plants and aminoacids. These supplements could be contaminated, intentionally or unintentionally, with banned substances, mostly prohormones in low concentrations and/or active ingredients could be misrepresented on the label. The health risk is high, especially for pregnant women, women and children due to gender differences in sex-steroid hormone synthesis. Professionals in many disciplines should inform their patients that supplements are drugs and that consultation is needed before and during their use.

\section{Drug-induced hyperandrogenemia}

Hyperandrogenemia is suspected in a female of any age in the presence of hyperandrogenic signs such as hirsutism, hypetrichosis, acne, clitoromegaly and deepening of the voice. Specifically, if a patient exhibits terminal hair (long, thick and pigmented) located in scalp, eyebrows, eyelashes, face and pubis then the diagnosis of druginduced hypertrichosis is not substantiated. On the other hand, the presence of vellus hair (short, fine, non-pigmented) located anywhere else from the abovementioned areas of the body, strengthens the possibility of drug-induced hypertrichosis (223). However, it should be differentiated from hirsutism because it is independent of androgen stimulation. Drugs usually associated with this phenomenon are cyclosporine, acitretin, azelaic acid, cetirizine, citalopram, topical corticosteroids, diazoxide, penicillamine, phenytoin, streptomycin and minoxidil (224). Nevertheless, in the presence of a female with hirsutism the diagnosis of drug-induced hyperandrogenemia is a diagnosis of exclusion and several causes such as PCOS, non-classical CAH, ovarian hyperthecosis and ovarian/adrenocortical carcinoma 
must be ruled out by appropriate testing. Additionally, a thorough and detailed review of medical and drug history will guide the diagnosis.

Regarding the presence of increased androgen levels in the blood of a female, the first drug that should be excluded is testosterone. The gradual decrease of testosterone during menopause has been associated with the loss of sexual desire in a significant proportion of postmenopausal women, given the principal role of testosterone in female sexuality. Based on this notion, several experiments of testosterone administration have shown a significant improvement on different aspects of sexual function such as sexual fantasies, desire and engagement and these actions are directly related to increased levels of bioavailable testosterone levels (225). This approach has led to the enormous number of two million prescriptions for off-label compounded formulations of testosterone for women in 2006-2007 in USA. Since women are prescribed testosterone at various dosages and different formulations, an unknown percentage might be receiving more than the suggested dose of just $300 \mu \mathrm{g}$ daily with unknown effects.

The widespread use of supplements is another important and common cause of hyperandrogenemia in women. Of note the gold stone in this market is DHEA supplements. Although beneficial effects of DHEA supplementation has not been demonstrated universally, the oral consumption of a moderate dose of $50 \mathrm{mg}$ DHEA for 12 months has doubled circulating testosterone levels in postmenopausal women (226).

A common disorder associated with drug-induced hyperandrogenemia is epilepsy. This observation should be attributed to two different facts. First, epilepsy per se is a state associated with dysregulation of GnRH pulse generator due to neuronal paroxysmal discharges (227). Second, the use of valproate, an effective antiepileptic drug is linked to several aspects of androgen production. Namely, valproate induces centrally mediated modification of GABA-ergic neurotransmission leading to reduced serum gonadotropin levels. Additionally, valproate exerts direct effect on follicular steroidogenesis in the ovary leading to increased $\Delta 4 \mathrm{~A}$ levels (228). Finally, the induction of CYP17 and CYP11A genes by valproate leads to higher androgens levels. The total effects of valproate in circulating androgen levels can be summarized as follows: increased total testosterone levels, free androgen index, SHBG, $\Delta 4 \mathrm{~A}$ and decreased estradiol levels (229). Regarding the others classes of drugs used in the treatment of epilepsy such as phenobarbital, phenytoin, carbamazepine the induction of hepatic microsomal enzymes, leads to increased SHBG production and reduction of free, circulating androgen and estrogen concentrations.

\section{Drug-induced PCOS}

PCOS is a clinical entity that In fact a plethora of drugs can act on multiple levels of its multifactorial etiology, including reproductive and metabolic axes (Fig. 3). Druginduced PCOS can be defined as the manifestation of PCOS symptoms and signs, originating from drugs that can either unravel an underlying, preexisting PCOS or induce hormonal/metabolic signs and symptoms imitating PCOS. Analogously to the intrinsic diagnostic difficulties of the syndrome, drug-induced PCOS may be equally diagnostically challenging.

\section{Drugs that can unravel preexisting PCOS}

Multiple drug categories that can can promote weight gain and obesity, including tricyclic antidepressants, SSRIS, atypical antipsychotics, lithium, anticonvulsants and antidiabetic agents, can lead a PCOS prone background to metabolic dysfunction, insulin resistance and compensatory hyperinsulinemia, which may further potentiate androgen excess, contributing to unraveling a clinically silent and occult PCOS (230). In this context, a meticulous history and clinical examination, along with high clinical suspicion, are paramount in order to reveal pharmaceutical causes that can trigger the clinical manifestation of PCOS components and prevent a possible PCOS misdiagnosis.

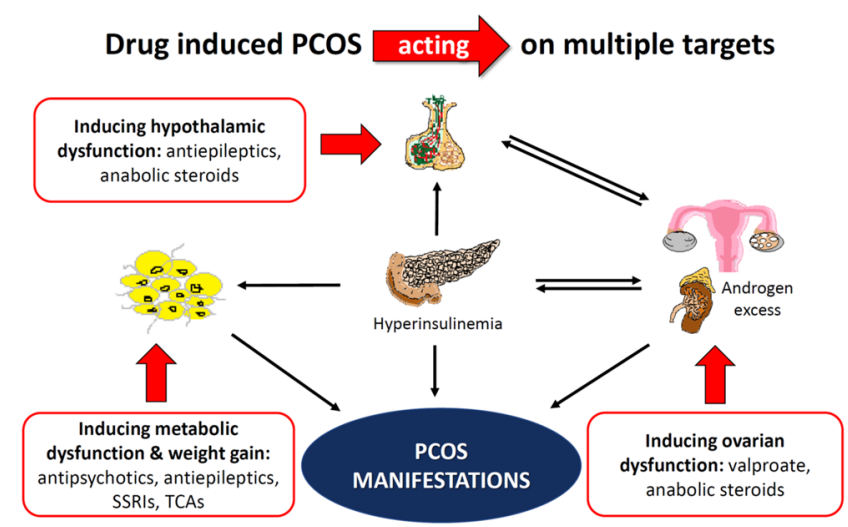

Figure 3

Pathophysiological mechanisms underlying drug-induced PCOS. 
Drugs inducing the complete spectrum of PCOS syndrome

In 1993, Isojärvi and coworkers published the first scientific data that in reproductive-aged women treated with valproate (VPA) for epilepsy, most of them had cardinal features of PCOS, including increased testosterone blood levels and polycystic ovarian morphology (231). A decade later, Nelson-DeGrave et al. provided analogous biochemical data, in which long-term cultures of theca cells isolated from follicles of women treated with VPA for 72 hours displayed increased steroidogenesis, in comparison with normal ovulating women. The observed increment of stimulated steroidogenesis was attributed to changes in chromatin modifications (histone acetylation) that augment transcription of steroidogenic genes. Interestingly, the most pronounced effect of VPA on androgen biosynthesis was observed in the dose range of 300-3000 microm, which represents the therapeutic levels in the treatment of epilepsy and bipolar disorder (232). Furthermore, the same research group showed that VPA can also induce a PCOS-like genomic phenotype, via the observation that VPA- and PCOS-induced changes in gene expression (enhanced Akt/PKB signal transduction) in human theca cells were similar (233).

Apart from the effects in androgen biosynthesis, VPA can also disrupt normal hypothalamic signaling, leading not only to LH/FSH altered secretion but also to increased appetite and, thereby, weight gain. The observed deregulation in multiple pathways of female metabolic and reproductive axes represents a pathophysiological process very similar to that of PCOS and leads to a clinical phenotype mimicking this syndrome (Fig. 4) (234).

Although epilepsy per se has been associated with various reproductive endocrine disorders, including PCOS (via perturbing the hypothalamic-pituitary axis), all the above experimental and clinical data have consistently proved that VPA treatment is associated with PCOS manifestation. A meta-analysis by Hu et al., involving 11 studies and 556 women with epilepsy treated with VPA, 593 women treated with other antiepileptic drugs (AEDs), 120 women with untreated epilepsy and 329 healthy controls, has also verified this close association. The raw incidence of PCOS in VPA-treated epileptic women was significantly higher (approximately 1.95-fold) with respect to nontreated patients, although some differences in the results were detected according to different definitions or diagnostic criteria of PCOS (235).

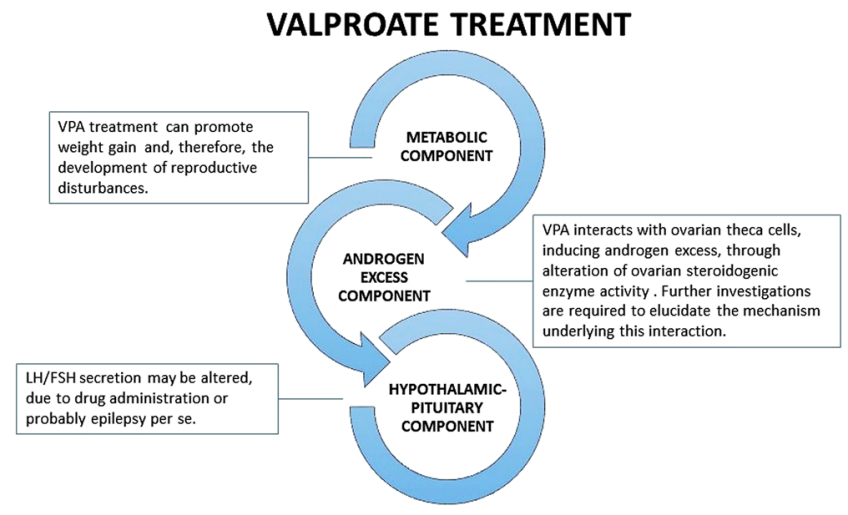

DEREGULATION IN MULTIPLE PATHWAYS, EXACTLY LIKE PCOS.

\section{Figure 4}

Valproate induces deregulations in multiple pathways of female metabolic and reproductive axes, creating a pathophysiological process very similar to that of PCOS.

\section{Drug-induced male infertility and sperm abnormalities}

Studying the reproductive effects of a drug may be challenging, since a compound may affect male fertility in many ways: either by causing sexual dysfunction (including erectile or/and ejaculation dysfunction) or by disrupting spermatogenesis; the latter as a result of insults targeting the HPG axis, the seminiferous epithelium, semen transition and maturation or combinations of the above (236).

The detrimental effects of exogenous androgen administration on male fertility are well established. Landmark studies supported by WHO have shown that exogenous testosterone (T) with or without progestins leads up to $95 \%$ of men to severe oligospermia $\left(<10^{6}\right.$ sperm/ $\mathrm{mL}$ ) by suppressing the HPG axis and diminishing intratesticular T levels. These effects on sperm parameters are generally reversible within 3-12 months after stopping $\mathrm{T}$ and the recovery time depends on age, testosterone dose, route of administration and duration of treatment (Fig. 5) (237).

On the other hand, spermatogenesis may be affected by drugs that diminish or hamper the action of $\mathrm{T}$ (e.g. anti-androgens). Cyproterone acetate is a progestin with anti-androgenic properties used in the palliative treatment for prostate cancer, which is associated with a reversible decrease in sperm parameters and is accompanied by symptoms of androgen deprivation such as loss of erectile function and libido (238). Similarly GnRH agonists or antagonists desensitize or block the GnRH pituitary receptors respectively, resulting in 'chemical' castration. 
Suppression and Recovery of Human Sperm Output: WHO Studies Sperm concentration

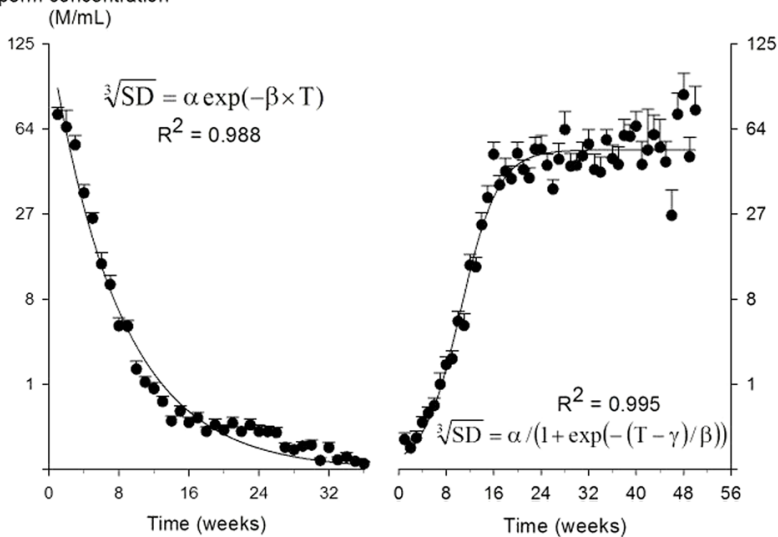

\section{Figure 5}

Suppression of sperm output after testosterone ( $\mathrm{T}$ ) administration for contraception and recovery after $T$ discontinuation, using pooled data from the WHO contraceptive studies. Data points represent sperm concentration mean and SE (error bar) of semen samples grouped within weeks. Sperm concentration fell in the majority of samples below 1 million $/ \mathrm{mL}$ in 12 weeks after T administration, whereas almost all individuals were expected to recover by 24 months after discontinuation. Note cube-root scale on the y-axis. Reprinted with permission by Ly et al. (237).

A relevant class of drugs, frequently prescribed for benign prostate hyperplasia are $5 \alpha$-reductase inhibitors (5-ARI), such as finasteride and dutasteride, which block the conversion of $\mathrm{T}$ to its drastic metabolite Dihydrotestosterone. These drugs have well-documented negative effects on libido and erectile function, which may persist several months after discontinuation ('Post Finasteride Syndrome') (239). 5-ARIs can also significantly decrease sperm count and mobility; however, this effect is insufficient to reduce fertility in men with normal semen prior to treatment. The above side effects are generally less common among men treated with lower doses of 5-ARIs for male-pattern baldness (240).

Psychotropic drugs also have profound negative effects on male fertility and include antidepressants, antipsychotics and recreational drugs, such as opioids and cannabis. This may be attributed to a central action of elevated serotonin on the hypothalamus, moderate elevation of PRL and possibly a direct action on smooth muscle cells. One should consider that ejaculatory dysfunction is also prevalent among untreated men with depression as well (240).

The most popular and studied antidepressants with respect to male fertility are SSRIs which may increase ejaculatory latency up to $50-65 \%$, while in $5.6 \%$ of patients they cause retrograde ejaculation. Treatment with SSRIs may negatively affect sperm quality - especially sperm DNA fragmentation, an effect seen as soon as 4 weeks after the initiation of therapy, which is possibly a result of abnormal epididymal sperm transit rather than a defect of spermatogenesis (241). Non-SSRI antidepressants such as norepinephrine/dopamine reuptake inhibitors (NDRIs) and serotonin antagonists and reuptake inhibitors (SARIs) have minimal sexual side effects and could be used as alternatives to SSRIs in men with sexual dysfunction, while their effects on semen quality have not been assessed so far (242).

Regarding chemotherapy, many chemotherapeutic drugs cross the blood-testis barrier and cause irreversible damage of the germ-cells and the seminiferous epithelium. Alkylating agents and especially mustine are associated with almost $100 \%$ permanent azoospermia, while platin-based regiments show long-term spermatogenesis recovery. Various cytoprotective strategies have been applied to minimize these side effects, such as prophylactic downregulation of the HPG axis with GnRH agonists/ testosterone; however, pretreatment sperm cryopreservation represents the most rational option (243).

Some of these cytotoxic agents such as cyclophosphamide have been used in lower doses as immunosuppressants for the treatment of severe, chronic inflammatory diseases (e.g. SLE). Similarly the risk of sustained azoospermia or oligozoospermia reaches $90 \%$ and cryopreservation prior to therapy should be recommended. Other immunosuppressant drugs that impact negatively fertility are purine metabolism disruptors (azathioprine, methotrexate). Regarding methotrexate, there is evidence from animal models of gonadotoxic and probably teratogenic action, whereas evidence in men is limited (244). On the contrary data on azathioprine/mercaptopurine has shown no significant changes in semen quality during treatment or congenital anomalies in the offspring, representing alternative options in men who seek fertility (245).

Antihypertensives are also well known to cause sexual dysfunction, including both erectile and ejaculatory dysfunction, whereas there is insufficient evidence to link their use with testicular dysfunction. Their negative impact is generally related to the decrease of pressure and the net hydraulic effects that it may have on erection, while specific actions are mediated by receptor binding. Peripheral $\beta 1$-adrenergic antagonists and especially atenolol are associated with erectile dysfunction (ED), an effect seen less often with 'cardioselective' beta-blockers 
such as nebivolol (246). Mineralcorticoid receptor antagonists, such as spironolactone disrupt androgen action by exerting a peripheral anti-androgen effect due to cross-reactivity with the androgen receptor, effects that can be ameliorated by the use of the more selective blocker eplerenone.

Miscellaneous drugs used in everyday practice have been implicated in derangement of male reproductive function. Metoclopramide is an antagonist of the dopamine receptor 2, used for nausea and vomiting and is well known to increase PRL levels; however, there are no data on detrimental effects on the HPG axis or on semen parameters (247). Interestingly paracetamol, possibly the most frequently consumed painkiller, has been shown to cause sperm abnormalities, including DNA fragmentation, and to increase time to pregnancy, effects that are reversible and dose related (248). A possible mechanism for this effect is the ability of paracetamol to decrease prostaglandins, which are relevant to the fertilization capacity of spermatozoa (249). Statins finally are thought to cause a possible decrease in $\mathrm{T}$ levels due to depletion of the substrates of steroidogenesis as well as disruption of sperm membranes which are particularly rich in cholesterol. Nevertheless, low level of evidence exists only for Simvastatin and Pravastatin (250).

\section{Conclusions}

In the era of polypharmacy, this review aimed to cover a contemporary topic, the drug-induced endocrinopathies, which was presented at the monothematic annual Combo Endo Course 2018. This challenging part of endocrinology is constantly expanding particularly during the last decade, with the new oncological therapeutic agents, targeting novel molecular pathways in the process of malignancies. In this new era of drug-induced endocrine disease, clinicians should be aware that drugs can cause endocrine abnormalities via different mechanisms and mimic a variety of clinical scenarios. In the context of the delicate balance of the endocrine system, even imperceptible drug-induced deregulations can lead to a clinical expressed endocrinopathy. Therefore, clinicians should not only promptly recognize drug-induced hormonal and metabolic abnormalities, but more importantly proceed on time therapeutically.

\section{Declaration of interest}

The authors declare that there is no conflict of interest that could be perceived as prejudicing the impartiality of this review.

\section{Funding}

V Popovic: This study was supported by a grant from the Ministry of Science of Republic of Serbia (Project 175033). The rest of the authors did not receive any specific grant from any funding agency in the public, commercial or not-for-profit sector.

\section{References}

1 Masnoon N, Shakib S, Kalisch-Ellett L \& Caughey GE. What is polypharmacy? A systematic review of definitions. BMC Geriatrics 201717 230. (https://doi.org/10.1186/s12877-017-0621-2)

2 Gu Q, Dillon CF \& Burt VL. Prescription drug use continues to increase: U.S. prescription drug data for 2007-2008. NCHS Data Brief 2010 1-8. (https://doi.org/10.1037/e665492010-001)

3 Sutherland JJ, Daly TM, Liu X, Goldstein K, Johnston JA \& Ryan TP. Co-prescription trends in a large cohort of subjects predict substantial drug-drug interactions. PLoS ONE 201510 e0118991. (https://doi.org/10.1371/journal.pone.0118991)

4 Shehab N, Lovegrove MC, Geller AI, Rose KO, Weidle NJ \& Budnitz DS. US Emergency Department visits for outpatient adverse drug events, 2013-2014. JAMA 2016316 2115-2125. (https://doi. org/10.1001/jama.2016.16201)

5 Sultana J, Cutroneo P \& Trifiro G. Clinical and economic burden of adverse drug reactions. Journal of Pharmacology and Pharmacotherapeutics 20134 S73-S77. (https://doi.org/10.4103/0976500X.120957)

6 Ben Salem C, Slim R, Elouni B, Hmouda H \& Bouraoui K. Druginduced endocrine and metabolic disorders. Drug Safety. $2007 \mathbf{3 0}$ 727-728; author reply 728-729. (https://doi.org/10.2165/00002018200730080-00009)

7 Sturgeon CM \& Viljoen A. Analytical error and interference in immunoassay: minimizing risk. Annals of Clinical Biochemistry 2011 48 418-432. (https://doi.org/10.1258/acb.2011.011073)

8 Coley WB. The treatment of malignant tumors by repeated inoculations of erysipelas. With a report of ten original cases. 1893. Clinical Orthopaedics and Related Research 1991 3-11.

9 Stewart TJ \& Smyth MJ. Improving cancer immunotherapy by targeting tumor-induced immune suppression. Cancer Metastasis Reviews 201130 125-140. (https://doi.org/10.1007/s10555-011-9280-5)

10 Byun DJ, Wolchok JD, Rosenberg LM \& Girotra M. Cancer immunotherapy - immune checkpoint blockade and associated endocrinopathies. Nature Reviews: Endocrinology 201713 195-207. (https://doi.org/10.1038/nrendo.2016.205)

11 Barroso-Sousa R, Barry WT, Garrido-Castro AC, Hodi FS, Min L, Krop IE \& Tolaney SM. Incidence of endocrine dysfunction following the use of different immune checkpoint inhibitor regimens: a systematic review and meta-analysis. JAMA Oncology 20184 173-182. (https://doi.org/10.1001/jamaoncol.2017.3064)

12 Piranavan P, Li Y, Brown E, Kemp EH \& Trivedi N. Immune checkpoint inhibitor-induced hypoparathyroidism associated with calcium-sensing receptor-activating autoantibodies. Journal of Clinical Endocrinology and Metabolism 2019104 550-556. (https://doi. org/10.1210/jc.2018-01151)

13 Michot JM, Bigenwald C, Champiat S, Collins M, Carbonnel F, Postel-Vinay S, Berdelou A, Varga A, Bahleda R, Hollebecque A et al. Immune-related adverse events with immune checkpoint blockade: a comprehensive review. European Journal of Cancer 201654 139-148. (https://doi.org/10.1016/j.ejca.2015.11.016)

14 Ryder M, Callahan M, Postow MA, Wolchok J \& Fagin JA. Endocrinerelated adverse events following ipilimumab in patients with advanced melanoma: a comprehensive retrospective review from a single institution. Endocrine-Related Cancer 201421 371-381. (https:// doi.org/10.1530/ERC-13-0499)

15 Delivanis DA, Gustafson MP, Bornschlegl S, Merten MM, Kottschade L, Withers S, Dietz AB \& Ryder M. Pembrolizumab- 
induced thyroiditis: comprehensive clinical review and insights into underlying involved mechanisms. Journal of Clinical Endocrinology and Metabolism 2017102 2770-2780. (https://doi.org/10.1210/ jc.2017-00448)

16 Juszczak A, Gupta A, Karavitaki N, Middleton MR \& Grossman AB. Ipilimumab: a novel immunomodulating therapy causing autoimmune hypophysitis: a case report and review. European Journal of Endocrinology 2012167 1-5. (https://doi.org/10.1530/EJE-12-0167)

17 Faje AT, Sullivan R, Lawrence D, Tritos NA, Fadden R, Klibanski A \& Nachtigall L. Ipilimumab-induced hypophysitis: a detailed longitudinal analysis in a large cohort of patients with metastatic melanoma. Journal of Clinical Endocrinology and Metabolism 201499 4078-4085. (https://doi.org/10.1210/jc.2014-2306)

18 Albarel F, Gaudy C, Castinetti F, Carre T, Morange I, Conte-Devolx B, Grob JJ \& Brue T. Long-term follow-up of ipilimumab-induced hypophysitis, a common adverse event of the anti-CTLA-4 antibody in melanoma. European Journal of Endocrinology 2015172 195-204. (https://doi.org/10.1530/EJE-14-0845)

19 Zhao C, Tella SH, Del Rivero J, Kommalapati A, Ebenuwa I, Gulley J, Strauss J \& Brownell I. Anti-PD-L1 treatment induced central diabetes insipidus. Journal of Clinical Endocrinology and Metabolism 2018103 365-369. (https://doi.org/10.1210/jc.2017-01905)

20 Haugen BR. Drugs that suppress TSH or cause central hypothyroidism. Best Practice and Research Clinical Endocrinology and Metabolism 200923 793-800. (https://doi.org/10.1016/j. beem.2009.08.003)

21 Cappelli C, Rotondi M, Pirola I, Agosti B, Formenti A, Zarra E, Valentini U, Leporati P, Chiovato L \& Castellano M. Thyreotropin levels in diabetic patients on metformin treatment. European Journal of Endocrinology 2012167 261-265. (https://doi.org/10.1530/EJE-12-0225)

22 Dornelles Severo M, Sturmer Andrade T, Correa Junior V, Antonio Naujorks A, Gus M \& Schaan BD. Metformin effect on TSH in subclinical hypothyroidism: randomized, double-blind, placebocontrolled clinical trial. Endocrine 201859 66-71. (https://doi. org/10.1007/s12020-017-1462-7)

23 Min L, Hodi FS, Giobbie-Hurder A, Ott PA, Luke JJ, Donahue H, Davis M, Carroll RS \& Kaiser UB. Systemic high-dose corticosteroid treatment does not improve the outcome of ipilimumab-related hypophysitis: a retrospective cohort study. Clinical Cancer Research 201521 749-755. (https://doi.org/10.1158/1078-0432.CCR-14-2353)

24 Nagasaka M, Abdallah N, Samantray J \& Sukari A. Is this really just 'fatigue'? A case series of immune-related central adrenal insufficiency secondary to immune checkpoint inhibitors. Clinical Case Reports 20186 1278-1281. (https://doi.org/10.1002/ccr3.1567)

25 Lupu J, Pages C, Laly P, Delyon J, Laloi M, Petit A, Basset-Seguin N, Oueslati I, Zagdanski AM, Young J et al. Transient pituitary ACTHdependent Cushing syndrome caused by an immune checkpoint inhibitor combination. Melanoma Research 201727 649-652. (https://doi.org/10.1097/CMR.0000000000000405)

26 Higham CE, Olsson-Brown A, Carroll P, Cooksley T, Larkin J, Lorigan P, Morganstein D, Trainer PJ \& Society for Endocrinology Clinical Committee. SOCIETY FOR ENDOCRINOLOGY ENDOCRINE EMERGENCY GUIDANCE: Acute management of the endocrine complications of checkpoint inhibitor therapy. Endocrine Connections 20187 G1-G7. (https://doi.org/10.1530/EC-18-0068)

27 Faje AT, Lawrence D, Flaherty K, Freedman C, Fadden R, Rubin K, Cohen J \& Sullivan RJ. High-dose glucocorticoids for the treatment of ipilimumab-induced hypophysitis is associated with reduced survival in patients with melanoma. Cancer 2018124 3706-3714. (https://doi.org/10.1002/cncr.31629)

28 Torino F, Barnabei A, Paragliola RM, Marchetti P, Salvatori R \& Corsello SM. Endocrine side-effects of anti-cancer drugs: mAbs and pituitary dysfunction: clinical evidence and pathogenic hypotheses. European Journal of Endocrinology 2013169 R153-R164. (https://doi. org/10.1530/EJE-13-0434)
29 Iwama S, De Remigis A, Callahan MK, Slovin SF, Wolchok JD \& Caturegli P. Pituitary expression of CTLA-4 mediates hypophysitis secondary to administration of CTLA-4 blocking antibody. Science Translational Medicine 20146 230ra45. (https://doi.org/10.1126/ scitranslmed.3008002)

30 Caturegli P, Di Dalmazi G, Lombardi M, Grosso F, Larman HB, Larman T, Taverna G, Cosottini M \& Lupi I. Hypophysitis secondary to cytotoxic T-lymphocyte-associated protein 4 blockade: insights into pathogenesis from an autopsy series. American Journal of Pathology 2016186 3225-3235. (https://doi.org/10.1016/j. ajpath.2016.08.020)

31 Angelousi A, Chatzellis E \& Kaltsas G. New molecular, biological, and immunological agents inducing hypophysitis. Neuroendocrinology 2018106 89-100. (https://doi.org/10.1159/000480086)

32 Lin AL, Jonsson P, Tabar V, Yang TJ, Cuaron J, Beal K, Cohen M, Postow M, Rosenblum M, Shia J et al. Marked response of a hypermutated ACTH-secreting pituitary carcinoma to ipilimumab and nivolumab. Journal of Clinical Endocrinology and Metabolism 2018 103 3925-3930. (https://doi.org/10.1210/jc.2018-01347)

33 Ileana-Dumbrava E \& Subbiah V. Autoimmune hypophysitis. Lancet: Oncology 201819 e123. (https://doi.org/10.1016/S14702045(17)30577-6)

34 Hoorn EJ, van der Lubbe N \& Zietse R. SIADH and hyponatraemia: why does it matter? NDT Plus 20092 iii5-iii11. (https://doi. org/10.1093/ndtplus/sfp153)

35 Shepshelovich D, Schechter A, Calvarysky B, Diker-Cohen T, RozenZvi B \& Gafter-Gvili A. Medication-induced SIADH: distribution and characterization according to medication class. British Journal of Clinical Pharmacology 201783 1801-1807. (https://doi.org/10.1111/ bcp.13256)

36 van der Lubbe N, Thompson CJ, Zietse R \& Hoorn EJ. The clinical challenge of SIADH-three cases. NDT Plus 20092 iii20-iii24. (https:// doi.org/10.1093/ndtplus/sfp155)

37 Berghuis B, de Haan GJ, van den Broek MP, Sander JW, Lindhout D \& Koeleman BP. Epidemiology, pathophysiology and putative genetic basis of carbamazepine- and oxcarbazepine-induced hyponatremia. European Journal of Neurology 201623 1393-1399. (https://doi. org/10.1111/ene.13069)

38 Capozzi A, Scambia G, Pontecorvi A \& Lello S. Hyperprolactinemia: pathophysiology and therapeutic approach. Gynecological Endocrinology 201531 506-510. (https://doi.org/10.3109/09513590.2 015.1017810)

39 Luciano AA, Sherman BM, Chapler FK, Hauser KS \& Wallace RB. Hyperprolactinemia and contraception: a prospective study. Obstetrics and Gynecology 198565 506-510.

40 Ismail MS, Serour GI, Torsten U, Weitzel H \& Berlien HP. Elevated serum prolactin level with high-dose estrogen contraceptive pills. European Journal of Contraception and Reproductive Health Care 19983 45-50. (https://doi.org/10.3109/13625189809167485)

41 Melmed S, Casanueva FF, Hoffman AR, Kleinberg DL, Montori VM, Schlechte JA, Wass JA \& Endocrine Society. Diagnosis and treatment of hyperprolactinemia: an Endocrine Society clinical practice guideline. Journal of Clinical Endocrinology and Metabolism 201196 273-288. (https://doi.org/10.1210/jc.2010-1692)

42 Vilar L, Abucham J, Albuquerque JL, Araujo LA, Azevedo MF, Boguszewski CL, Casulari LA, Cunha Neto MBC, Czepielewski MA, Duarte FHG et al. Controversial issues in the management of hyperprolactinemia and prolactinomas - an overview by the Neuroendocrinology Department of the Brazilian Society of Endocrinology and Metabolism. Archives of Endocrinology and Metabolism 201862 236-263. (https://doi.org/10.20945/23593997000000032)

43 Volavka J, Czobor P, Cooper TB, Sheitman B, Lindenmayer JP, Citrome L, McEvoy JP \& Lieberman JA. Prolactin levels in schizophrenia and schizoaffective disorder patients treated with 
clozapine, olanzapine, risperidone, or haloperidol. Journal of Clinical Psychiatry 200465 57-61. (https://doi.org/10.4088/JCP.v65n0109)

44 Cloutier M, Greene M, Touya M, Gagnon-Sanschagrin P \& Guerin A. A real-world analysis of healthcare costs and relative risk of hyperprolactinemia associated with antipsychotic treatments in the United States. Journal of Medical Economics 201821 1183-1190. (https://doi.org/10.1080/13696998.2018.1521415)

45 Carvalho AF, Sharma MS, Brunoni AR, Vieta E \& Fava GA. The safety, tolerability and risks associated with the use of newer generation antidepressant drugs: a critical review of the literature. Psychotherapy and Psychosomatics 201685 270-288. (https://doi. org/10.1159/000447034)

46 Arze RS, Ramos JM, Rashid HU \& Kerr DN. Amenorrhoea, galactorrhoea, and hyperprolactinaemia induced by methyldopa. British Medical Journal 1981283 194. (https://doi.org/10.1136/ bmj.283.6285.194)

47 Farag AGA, Basha MA, Amin SA, Elnaidany NF, Elhelbawy NG, Mostafa MMT, Khodier SA, Ibrahem RA \& Mahfouz RZ. Tramadol (opioid) abuse is associated with a dose- and time-dependent poor sperm quality and hyperprolactinaemia in young men. Andrologia 201850 e13026. (https://doi.org/10.1111/and.13026)

48 Trajanovska AS, Vujovic V, Ignjatova L, Janicevic-Ivanovska D \& Cibisev A. Sexual dysfunction as a side effect of hyperprolactinemia in methadone maintenance therapy. Medical Archives 201367 48-50. (https://doi.org/10.5455/medarh.2013.67.48-50)

49 Yoon HW, Lee JS, Park SJ, Lee SK, Choi WJ, Kim TY, Hong CH, Seok JH, Park IH, Son SJ et al. Comparing the effectiveness and safety of the addition of and switching to aripiprazole for resolving antipsychotic-induced hyperprolactinemia: a multicenter, openlabel, prospective study. Clinical Neuropharmacology 201639 288-294. (https://doi.org/10.1097/WNF.0000000000000175)

50 Montejo ÁL, Arango C, Bernardo M, Carrasco JL, Crespo-Facorro B, Cruz JJ, Del Pino-Montes J, Garcia-Escudero MA, Garcia-Rizo C, Gonzalez-Pinto A et al. Multidisciplinary consensus on the therapeutic recommendations for iatrogenic hyperprolactinemia secondary to antipsychotics. Frontiers in Neuroendocrinology 201745 25-34. (https://doi.org/10.1016/j.yfrne.2017.02.003)

51 Auriemma RS, Galdiero M, Vitale P, Granieri L, Lo Calzo F, Salzano C, Ferreri L, Pivonello C, Cariati F, Coppola G et al. Effect of chronic cabergoline treatment and testosterone replacement on metabolism in male patients with prolactinomas. Neuroendocrinology 2015101 66-81. (https://doi.org/10.1159/000371851)

52 Manchikanti L, Kaye AM, Knezevic NN, McAnally H, Slavin K, Trescot AM, Blank S, Pampati V, Abdi S, Grider JS et al. Responsible, safe, and effective prescription of opioids for chronic non-cancer pain: American Society of Interventional Pain Physicians (ASIPP) guidelines. Pain Physician 201720 S3-S92.

53 Vuong C, Van Uum SH, O'Dell LE, Lutfy K \& Friedman TC. The effects of opioids and opioid analogs on animal and human endocrine systems. Endocrine Reviews 201031 98-132. (https://doi. org/10.1210/er.2009-0009)

54 Bawor M, Bami H, Dennis BB, Plater C, Worster A, Varenbut M, Daiter J, Marsh DC, Steiner M, Anglin R et al. Testosterone suppression in opioid users: a systematic review and metaanalysis. Drug and Alcohol Dependence 2015149 1-9. (https://doi. org/10.1016/j.drugalcdep.2015.01.038)

55 Fountas A, Chai ST, Kourkouti C \& Karavitaki N. Mechanisms in endocrinology: endocrinology of opioids. European Journal of Endocrinology 2018179 R183-R196. (https://doi.org/10.1530/EJE18-0270)

56 Narayanaswamy S, Prague JK, Jayasena CN, Papadopoulou DA, Mizamtsidi M, Shah AJ, Bassett P, Comninos AN, Abbara A, Bloom SR et al. Investigating the KNDy hypothesis in humans by coadministration of kisspeptin, neurokinin B, and naltrexone in men. Journal of Clinical Endocrinology and Metabolism 2016101 3429-3436. (https://doi.org/10.1210/jc.2016-1911)
57 Ragni G, De Lauretis L, Bestetti O, Sghedoni D \& Gambaro V. Gonadal function in male heroin and methadone addicts. International Journal of Andrology 198811 93-100. (https://doi. org/10.1111/j.1365-2605.1988.tb00984.x)

58 Cicero TJ, Bell RD, Wiest WG, Allison JH, Polakoski K \& Robins E. Function of the male sex organs in heroin and methadone users. New England Journal of Medicine 1975292 882-887. (https://doi. org/10.1056/NEJM197504242921703)

59 Pelosi MA, Sama JC, Caterini H \& Kaminetzky HA. Galactorrheaamenorrhea syndrome associated with heroin addiction. American Journal of Obstetrics and Gynecology 1974118 966-970. (https://doi. org/10.1016/0002-9378(74)90667-X)

60 Roberts LJ, Finch PM, Pullan PT, Bhagat CI \& Price LM. Sex hormone suppression by intrathecal opioids: a prospective study. Clinical Journal of Pain 200218 144-148. (https://doi.org/10.1097/00002508200205000-00002)

61 Daniell HW. Hypogonadism in men consuming sustained-action oral opioids. Journal of Pain 20023 377-384. (https://doi.org/10.1054/ jpai.2002.126790)

62 Abs R, Verhelst J, Maeyaert J, Van Buyten JP, Opsomer F, Adriaensen H, Verlooy J, Van Havenbergh T, Smet M \& Van Acker K. Endocrine consequences of long-term intrathecal administration of opioids. Journal of Clinical Endocrinology and Metabolism 200085 2215-2222. (https://doi.org/10.1210/jcem.85.6.6615)

63 Rubinstein A \& Carpenter DM. Elucidating risk factors for androgen deficiency associated with daily opioid use. American Journal of Medicine 2014127 1195-1201. (https://doi.org/10.1016/j. amjmed.2014.07.015)

64 Rubinstein AL, Carpenter DM \& Minkoff JR. Hypogonadism in men with chronic pain linked to the use of long-acting rather than shortacting opioids. Clinical Journal of Pain 201329 840-845. (https://doi. org/10.1097/AJP.0b013e31827c7b5d)

65 Finch PM, Roberts LJ, Price L, Hadlow NC \& Pullan PT. Hypogonadism in patients treated with intrathecal morphine. Clinical Journal of Pain 200016 251-254. (https://doi. org/10.1097/00002508-200009000-00011)

66 Policola C, Stokes V, Karavitaki N \& Grossman A. Adrenal insufficiency in acute oral opiate therapy. Endocrinology, Diabetes and Metabolism Case Reports 20142014 130071. (https://doi.org/10.1530/EDM-13-0071)

67 Mussig K, Knaus-Dittmann D, Schmidt H, Morike K \& Haring HU. Secondary adrenal failure and secondary amenorrhoea following hydromorphone treatment. Clinical Endocrinology 200766 604-605. (https://doi.org/10.1111/j.1365-2265.2007.02779.x)

68 Rittmaster RS, Cutler Jr GB, Sobel DO, Goldstein DS, Koppelman MC, Loriaux DL \& Chrousos GP. Morphine inhibits the pituitary-adrenal response to ovine corticotropin-releasing hormone in normal subjects. Journal of Clinical Endocrinology and Metabolism 198560 891-895. (https://doi.org/10.1210/jcem-60-5-891)

69 Bershad AK, Jaffe JH, Childs E \& de Wit H. Opioid partial agonist buprenorphine dampens responses to psychosocial stress in humans. Psychoneuroendocrinology 201552 281-288. (https://doi. org/10.1016/j.psyneuen.2014.12.004)

70 Watanabe K, Kashiwagi K, Kamiyama T, Yamamoto M, Fukunaga M, Inada E \& Kamiyama Y. High-dose remifentanil suppresses stress response associated with pneumoperitoneum during laparoscopic colectomy. Journal of Anesthesia 201428 334-340. (https://doi. org/10.1007/s00540-013-1738-x)

71 Das G. Chronic heroin dependence leading to adrenal insufficiency. Case Reports in Endocrinology 20142014 461816. (https://doi. org $/ 10.1155 / 2014 / 461816$ )

72 Oltmanns KM, Fehm HL \& Peters A. Chronic fentanyl application induces adrenocortical insufficiency. Journal of Internal Medicine 2005 257 478-480. (https://doi.org/10.1111/j.1365-2796.2005.01483.x)

73 Gibb FW, Stewart A, Walker BR \& Strachan MW. Adrenal insufficiency in patients on long-term opioid analgesia. Clinical Endocrinology 201685 831-835. (https://doi.org/10.1111/cen.13125) 
74 Girotra M, Hansen A, Farooki A, Byun DJ, Min L, Creelan BC, Callahan MK, Atkins MB, Sharon E, Antonia SJ et al. The current understanding of the endocrine effects from immune checkpoint inhibitors and recommendations for management. JNCI Cancer Spectrum 20182 pky021. (https://doi.org/10.1093/jncics/pky021)

75 Mitchell AL, Cordell HJ, Soemedi R, Owen K, Skinningsrud B, Wolff AB, Ericksen M, Undlien D, Husebye E \& Pearce SH. Programmed death ligand 1 (PD-L1) gene variants contribute to autoimmune Addison's disease and Graves' disease susceptibility. Journal of Clinical Endocrinology and Metabolism 200994 5139-5145. (https://doi.org/10.1210/jc.2009-1404)

76 Orlov S, Salari F, Kashat L \& Walfish PG. Induction of painless thyroiditis in patients receiving programmed death 1 receptor immunotherapy for metastatic malignancies. Journal of Clinical Endocrinology and Metabolism 2015100 1738-1741. (https://doi. org/10.1210/jc.2014-4560)

77 Osorio JC, Ni A, Chaft JE, Pollina R, Kasler MK, Stephens D, Rodriguez C, Cambridge L, Rizvi H, Wolchok JD et al. Antibodymediated thyroid dysfunction during T-cell checkpoint blockade in patients with non-small-cell lung cancer. Annals of Oncology 201728 583-589. (https://doi.org/10.1093/annonc/mdw640)

78 Min L, Vaidya A \& Becker C. Thyroid autoimmunity and ophthalmopathy related to melanoma biological therapy. European Journal of Endocrinology 2011164 303-307. (https://doi.org/10.1530/ EJE-10-0833)

79 Borodic G, Hinkle DM \& Cia Y. Drug-induced graves disease from CTLA-4 receptor suppression. Ophthalmic Plastic and Reconstructive Surgery 201127 e87-e88. (https://doi.org/10.1097/ IOP.0b013e3181ef72a1)

80 Campredon P, Imbert P, Mouly C, Grunenwald S, Mazieres J \& Caron P. Severe inflammatory ophthalmopathy in a euthyroid patient during nivolumab treatment. European Thyroid Journal 20187 84-87. (https://doi.org/10.1159/000485742)

81 Di Stefano G, La Cesa S, Truini A \& Cruccu G. Natural history and outcome of 200 outpatients with classical trigeminal neuralgia treated with carbamazepine or oxcarbazepine in a tertiary centre for neuropathic pain. Journal of Headache and Pain 201415 34. (https:// doi.org/10.1186/1129-2377-15-34)

82 Wolchok JD, Kluger H, Callahan MK, Postow MA, Rizvi NA, Lesokhin AM, Segal NH, Ariyan CE, Gordon RA, Reed K et al. Nivolumab plus ipilimumab in advanced melanoma. New England Journal of Medicine 2013369 122-133. (https://doi.org/10.1056/NEJMoa1302369)

83 Tawbi HA, Forsyth PA, Algazi A, Hamid O, Hodi FS, Moschos SJ, Khushalani NI, Lewis K, Lao CD, Postow MA et al. Combined nivolumab and ipilimumab in melanoma metastatic to the brain. New England Journal of Medicine 2018379 722-730. (https://doi. org/10.1056/NEJMoa1805453)

84 Postow MA, Chesney J, Pavlick AC, Robert C, Grossmann K, McDermott D, Linette GP, Meyer N, Giguere JK, Agarwala SS et al. Nivolumab and ipilimumab versus ipilimumab in untreated melanoma. New England Journal of Medicine 2015372 2006-2017. (https://doi.org/10.1056/NEJMoa1414428)

85 Iyer PC, Cabanillas ME, Waguespack SG, Hu MI, Thosani S, Lavis VR, Busaidy NL, Subudhi SK, Diab A \& Dadu R. Immune-related thyroiditis with immune checkpoint inhibitors. Thyroid 201828 1243-1251. (https://doi.org/10.1089/thy.2018.0116)

86 Lee H, Hodi FS, Giobbie-Hurder A, Ott PA, Buchbinder EI, Haq R, Tolaney S, Barroso-Sousa R, Zhang K, Donahue H et al. Characterization of thyroid disorders in patients receiving immune checkpoint inhibition therapy. Cancer Immunology Research 20175 1133-1140. (https://doi.org/10.1158/2326-6066.CIR-17-0208)

87 Puzanov I, Diab A, Abdallah K, Bingham 3rd CO, Brogdon C, Dadu R, Hamad L, Kim S, Lacouture ME, LeBoeuf NR et al. Managing toxicities associated with immune checkpoint inhibitors: consensus recommendations from the Society for Immunotherapy of Cancer (SITC) Toxicity Management Working Group. Journal for
ImmunoTherapy of Cancer 20175 95. (https://doi.org/10.1186/s40425017-0300-z)

88 Brahmer JR, Lacchetti C, Schneider BJ, Atkins MB, Brassil KJ, Caterino JM, Chau I, Ernstoff MS, Gardner JM, Ginex P et al. Management of immune-related adverse events in patients treated with immune checkpoint inhibitor therapy: American Society of Clinical Oncology clinical practice guideline. Journal of Clinical Oncology 2018 36 1714-1768. (https://doi.org/10.1200/JCO.2017.77.6385)

89 Decallonne B, Bartholome E, Delvaux V, D’Haeseleer M, El Sankari S, Seeldrayers P, Van Wijmeersch B \& Daumerie C. Thyroid disorders in alemtuzumab-treated multiple sclerosis patients: a Belgian consensus on diagnosis and management. Acta Neurologica Belgica 2018118 153-159. (https://doi.org/10.1007/s13760-018-0883-2)

90 Ahmadieh H \& Salti I. Tyrosine kinase inhibitors induced thyroid dysfunction: a review of its incidence, pathophysiology, clinical relevance, and treatment. BioMed Research International 20132013 725410. (https://doi.org/10.1155/2013/725410)

91 Resteghini C, Cavalieri S, Galbiati D, Granata R, Alfieri S, Bergamini C, Bossi P, Licitra L \& Locati LD. Management of tyrosine kinase inhibitors (TKI) side effects in differentiated and medullary thyroid cancer patients. Best Practice and Research: Clinical Endocrinology and Metabolism 201731 349-361. (https://doi. org/10.1016/j.beem.2017.04.012)

92 Illouz F, Braun D, Briet C, Schweizer U \& Rodien P. Endocrine side-effects of anti-cancer drugs: thyroid effects of tyrosine kinase inhibitors. European Journal of Endocrinology 2014171 R91-R99. (https://doi.org/10.1530/EJE-14-0198)

93 Lambert CG, Mazurie AJ, Lauve NR, Hurwitz NG, Young SS, Obenchain RL, Hengartner NW, Perkins DJ, Tohen M \& Kerner B. Hypothyroidism risk compared among nine common bipolar disorder therapies in a large US cohort. Bipolar Disorders 201618 247-260. (https://doi.org/10.1111/bdi.12391)

94 Lazarus JH. Lithium and thyroid. Best Practice and Research: Clinical Endocrinology and Metabolism 200923 723-733. (https://doi. org/10.1016/j.beem.2009.06.002)

95 Perrild H, Hegedus L \& Arnung K. Sex related goitrogenic effect of lithium carbonate in healthy young subjects. Acta Endocrinologica 1984106 203-208. (https://doi.org/10.1530/acta.0.1060203)

96 Rao AS, Kremenevskaja N, Resch J \& Brabant G. Lithium stimulates proliferation in cultured thyrocytes by activating Wnt/beta-catenin signalling. European Journal of Endocrinology $2005153929-938$. (https://doi.org/10.1530/eje.1.02038)

97 Shih FY, Chuang YC, Chuang MJ, Lu YT, Tsai WC, Fu TY \& Tsai MH Effects of antiepileptic drugs on thyroid hormone function in epilepsy patients. Seizure 201748 7-10. (https://doi.org/10.1016/j. seizure.2017.03.011)

98 Zhang F, Kanzali P, Rubin V, Paras C \& Goldman J. Neuroleptic malignant syndrome with thyroid disorder: an unusual case report. Medicine 201796 e8191. (https://doi.org/10.1097/ MD.0000000000008191)

99 Foong AL, Grindrod KA, Patel T \& Kellar J. Demystifying serotonin syndrome (or serotonin toxicity). Canadian Family Physician Medecin de Famille Canadien 201864 720-727.

100 Diederichsen SZ, Darkner S, Chen X, Johannesen A, Pehrson S, Hansen J, Feldt-Rasmussen U \& Svendsen JH. Short-term amiodarone treatment for atrial fibrillation after catheter ablation induces a transient thyroid dysfunction: results from the placebo-controlled, randomized AMIO-CAT trial. European Journal of Internal Medicine 201633 36-41. (https://doi.org/10.1016/j.ejim.2016.04.012)

101 Ahmed S, Van Gelder IC, Wiesfeld AC, Van Veldhuisen DJ \& Links TP. Determinants and outcome of amiodarone-associated thyroid dysfunction. Clinical Endocrinology 201175 388-394. (https://doi.org/10.1111/j.1365-2265.2011.04087.x)

102 Martino E, Bartalena L, Bogazzi F \& Braverman LE. The effects of amiodarone on the thyroid. Endocrine Reviews 200122 240-254. (https://doi.org/10.1210/edrv.22.2.0427) 
103 Grober U \& Kisters K. Influence of drugs on vitamin D and calcium metabolism. Dermato-Endocrinology 20124 158-166. (https://doi. org/10.4161/derm.20731)

104 Cozzolino M, Vidal M, Arcidiacono MV, Tebas P, Yarasheski KE \& Dusso AS. HIV-protease inhibitors impair vitamin D bioactivation to 1,25-dihydroxyvitamin D. AIDS 200317 513-520. (https://doi. org/10.1097/01.aids.0000050817.06065.f8)

105 Eagling VA, Back DJ \& Barry MG. Differential inhibition of cytochrome $\mathrm{P} 450$ isoforms by the protease inhibitors, ritonavir, saquinavir and indinavir. British Journal of Clinical Pharmacology 1997 44 190-194. (https://doi.org/10.1046/j.1365-2125.1997.00644.x)

106 Dao CN, Patel P, Overton ET, Rhame F, Pals SL, Johnson C, Bush T, Brooks JT \& Study to Understand the Natural History of HIV and AIDS in the Era of Effective Therapy (SUN) Investigators. Low vitamin D among HIV-infected adults: prevalence of and risk factors for low vitamin D Levels in a cohort of HIV-infected adults and comparison to prevalence among adults in the US general population. Clinical Infectious Diseases 201152 396-405. (https://doi. org/10.1093/cid/ciq158)

107 Avihingsanon A, Kerr SJ, Ramautarsing RA, Praditpornsilpa K, Sophonphan J, Ubolyam S, Avihingsanon Y, Khovidhunkit W, Hiransuthikul N \& Ruxrungtham K. The association of gender, age, efavirenz use, and hypovitaminosis D among HIV-infected adults living in the tropics. AIDS Research and Human Retroviruses 201632 317-324. (https://doi.org/10.1089/AID.2015.0069)

108 Nylen H, Habtewold A, Makonnen E, Yimer G, Bertilsson L, Burhenne J, Diczfalusy U \& Aklillu E. Prevalence and risk factors for efavirenz-based antiretroviral treatment-associated severe vitamin D deficiency: a prospective cohort study. Medicine 201695 e4631. (https://doi.org/10.1097/MD.0000000000004631)

109 Fox J, Peters B, Prakash M, Arribas J, Hill A \& Moecklinghoff C. Improvement in vitamin D deficiency following antiretroviral regime change: results from the MONET trial. AIDS Research and Human Retroviruses 201127 29-34. (https://doi.org/10.1089/aid.2010.0081)

110 Ryom L, Boesecke C, Bracchi M, Ambrosioni J, Pozniak A, Arribas J, Behrens G, Mallon P, Puoti M, Rauch A et al. Highlights of the 2017 European AIDS Clinical Society (EACS) Guidelines for the treatment of adult HIV-positive persons version 9.0. HIV Medicine 201819 309-315. (https://doi.org/10.1111/hiv.12600)

111 Eckard AR, Thierry-Palmer M, Silvestrov N, Rosebush JC, O'Riordan MA, Daniels JE, Uribe-Leitz M, Labbato D, Ruff JH, Singh RJ et al. Effects of cholecalciferol supplementation on serum and urinary vitamin D metabolites and binding protein in HIVinfected youth. Journal of Steroid Biochemistry and Molecular Biology 2017168 38-48. (https://doi.org/10.1016/j.jsbmb.2017.01.018)

112 Havens PL, Stephensen CB, Van Loan MD, Schuster GU, Woodhouse LR, Flynn PM, Gordon CM, Pan CG, Rutledge B, Harris DR et al. Vitamin D3 supplementation increases spine bone mineral density in adolescents and young adults with human immunodeficiency virus infection being treated with tenofovir disoproxil fumarate: a randomized, placebo-controlled trial. Clinical Infectious Diseases 201866 220-228. (https://doi.org/10.1093/cid/cix753)

113 Fan HC, Lee HS, Chang KP, Lee YY, Lai HC, Hung PL, Lee HF \& Chi CS. The impact of anti-epileptic drugs on growth and bone metabolism. International Journal of Molecular Sciences 201617 E1242. (https://doi.org/10.3390/ijms17081242)

114 Teagarden DL, Meador KJ \& Loring DW. Low vitamin D levels are common in patients with epilepsy. Epilepsy Research 2014108 1352-1356. (https://doi.org/10.1016/j.eplepsyres.2014.06.008)

115 Tombini M, Palermo A, Assenza G, Pellegrino G, Benvenga A, Campana C, Naciu AM, Assenza F \& Lazzaro VD. Calcium metabolism serum markers in adult patients with epilepsy and the effect of vitamin D supplementation on seizure control. Seizure 2018 58 75-81. (https://doi.org/10.1016/j.seizure.2018.04.008)

116 Holick MF, Binkley NC, Bischoff-Ferrari HA, Gordon CM, Hanley DA, Heaney RP, Murad MH, Weaver CM \& Endocrine Society. Evaluation, treatment, and prevention of vitamin D deficiency: an Endocrine Society clinical practice guideline. Journal of Clinical Endocrinology and Metabolism 201196 1911-1930. (https://doi.org/10.1210/jc.2011-0385)

117 Kreutle V, Blum C, Meier C, Past M, Muller B, Schutz P \& Borm K. Bisphosphonate induced hypocalcaemia - report of six cases and review of the literature. Swiss Medical Weekly 2014144 w13979. (https://doi.org/10.4414/smw.2014.13979)

118 Body JJ, Niepel D \& Tonini G. Hypercalcaemia and hypocalcaemia: finding the balance. Supportive Care in Cancer 201725 1639-1649. (https://doi.org/10.1007/s00520-016-3543-1)

119 Lipton A, Fizazi K, Stopeck AT, Henry DH, Brown JE, Yardley DA, Richardson GE, Siena S, Maroto P, Clemens M et al. Superiority of denosumab to zoledronic acid for prevention of skeletal-related events: a combined analysis of 3 pivotal, randomised, phase 3 trials. European Journal of Cancer 201248 3082-3092. (https://doi. org/10.1016/j.ejca.2012.08.002)

120 Greeviroj P, Kitrungphaiboon T, Katavetin P, Praditpornsilpa K, Eiam-Ong S, Jaber BL \& Susantitaphong P. Cinacalcet for treatment of chronic kidney disease-mineral and bone disorder: a meta-analysis of randomized controlled trials. Nephron 2018139 197-210. (https:// doi.org/10.1159/000487546)

121 Floege J, Tsirtsonis K, Iles J, Drueke TB, Chertow GM \& Parfrey P. Incidence, predictors and therapeutic consequences of hypocalcemia in patients treated with Cinacalcet in the EVOLVE trial. Kidney International 201893 1475-1482. (https://doi.org/10.1016/j. kint.2017.12.014)

122 Diaz de Barboza G, Guizzardi S \& Tolosa de Talamoni N. Molecular aspects of intestinal calcium absorption. World Journal of Gastroenterology 201521 7142-7154. (https://doi.org/10.3748/wjg.v21.i23.7142)

123 Win MA, Thein KZ, Qdaisat A \& Yeung SJ. Acute symptomatic hypocalcemia from immune checkpoint therapy-induced hypoparathyroidism. American Journal of Emergency Medicine 201735 1039.e5-1039.e7. (https://doi.org/10.1016/j.ajem.2017.02.048)

124 Kassi E, Kapsali I, Kokkinos M \& Gogas H. Treatment of severe hypocalcaemia due to osteoblastic metastases in a patient with postthyroidectomy hypoparathyroidism with (153)Sm-EDTMP. BMJ Case Reports 20172017.

125 Mirza F \& Canalis E. Management of endocrine disease: secondary osteoporosis: pathophysiology and management. European Journal of Endocrinology 2015173 R131-R151. (https://doi.org/10.1530/ EJE-15-0118)

126 Rizzoli R \& Biver E. Glucocorticoid-induced osteoporosis: who to treat with what agent? Nature Reviews: Rheumatology 2015 11 98-109. (https://doi.org/10.1038/nrrheum.2014.188)

127 Canalis E, Mazziotti G, Giustina A \& Bilezikian JP. Glucocorticoidinduced osteoporosis: pathophysiology and therapy. Osteoporosis International 200718 1319-1328. (https://doi.org/10.1007/s00198007-0394-0)

128 Buckley L, Guyatt G, Fink HA, Cannon M, Grossman J, Hansen KE, Humphrey MB, Lane NE, Magrey M, Miller M et al. 2017 American College of Rheumatology guideline for the prevention and treatment of glucocorticoid-induced osteoporosis. Arthritis and Rheumatology 201769 1521-1537. (https://doi.org/10.1002/art.40137)

129 Saag KG, Zanchetta JR, Devogelaer JP, Adler RA, Eastell R, See K, Krege JH, Krohn K \& Warner MR. Effects of teriparatide versus alendronate for treating glucocorticoid-induced osteoporosis: thirty-six-month results of a randomized, double-blind, controlled trial. Arthritis and Rheumatism $2009603346-3355$. (https://doi. org/10.1002/art.24879)

130 Lekamwasam S, Adachi JD, Agnusdei D, Bilezikian J, Boonen S, Borgstrom F, Cooper C, Diez Perez A, Eastell R, Hofbauer LC et al. A framework for the development of guidelines for the management of glucocorticoid-induced osteoporosis. Osteoporosis International 2012 23 2257-2276. (https://doi.org/10.1007/s00198-012-1958-1)

131 Geisler J \& Lonning PE. Endocrine effects of aromatase inhibitors and inactivators in vivo: review of data and method limitations. Journal of 
Steroid Biochemistry and Molecular Biology 200595 75-81. (https://doi org/10.1016/j.jsbmb.2005.04.015)

132 Florencio-Silva R, Sasso GR, Sasso-Cerri E, Simoes MJ \& Cerri PS. Biology of bone tissue: structure, function, and factors that influence bone cells. BioMed Research International 20152015 421746. (https:// doi.org/10.1155/2015/421746)

133 Lee SJ, Kim KM, Brown JK, Brett A, Roh YH, Kang DR, Park BW \& Rhee Y. Negative impact of aromatase inhibitors on proximal femoral bone mass and geometry in postmenopausal women with breast cancer. Calcified Tissue International 201597 551-559. (https://doi. org/10.1007/s00223-015-0046-x)

134 Edwards BJ, Raisch DW, Shankaran V, McKoy JM, Gradishar W, Bunta AD, Samaras AT, Boyle SN, Bennett CL, West DP et al. Cancer therapy associated bone loss: implications for hip fractures in midlife women with breast cancer. Clinical Cancer Research 201117 560-568. (https://doi.org/10.1158/1078-0432.CCR-10-1595)

135 Hadji P, Aapro MS, Body JJ, Gnant M, Brandi ML, Reginster JY, Zillikens MC, Gluer CC, de Villiers T, Baber R et al. Management of aromatase inhibitor-associated bone loss (AIBL) in postmenopausal women with hormone sensitive breast cancer: joint position statement of the IOF, CABS, ECTS, IEG, ESCEO IMS, and SIOG. Journal of Bone Oncology 20177 1-12. (https://doi.org/10.1016/j. jbo.2017.03.001)

136 Rizzoli R, Body JJ, DeCensi A, Reginster JY, Piscitelli P, Brandi ML \& European Society for Clinical and Economical aspects of Osteoporosis and Osteoarthritis (ESCEO). Guidance for the prevention of bone loss and fractures in postmenopausal women treated with aromatase inhibitors for breast cancer: an ESCEO position paper. Osteoporosis International 201223 2567-2576. (https://doi.org/10.1007/s00198011-1870-0)

137 Gnant M, Pfeiler G, Dubsky PC, Hubalek M, Greil R, Jakesz R, Wette V, Balic M, Haslbauer F, Melbinger E et al. Adjuvant denosumab in breast cancer (ABCSG-18): a multicentre, randomised double-blind, placebo-controlled trial. Lancet $2015386433-443$. (https://doi.org/10.1016/S0140-6736(15)60995-3)

138 Early Breast Cancer Trialists' Collaborative Group (EBCTCG). Adjuvant bisphosphonate treatment in early breast cancer: meta-analyses of individual patient data from randomised trials. Lancet 2015386 1353-1361. (https://doi.org/10.1016/S01406736(15)60908-4)

139 Rachner TD, Coleman R, Hadji P \& Hofbauer LC. Bone health during endocrine therapy for cancer. Lancet: Diabetes and Endocrinology 2018 6 901-910. (https://doi.org/10.1016/S2213-8587(18)30047-0)

140 Greenspan SL, Coates P, Sereika SM, Nelson JB, Trump DL \& Resnick NM. Bone loss after initiation of androgen deprivation therapy in patients with prostate cancer. Journal of Clinical Endocrinology and Metabolism 200590 6410-6417. (https://doi. org/10.1210/jc.2005-0183)

141 Lassemillante AC, Doi SA, Hooper JD, Prins JB \& Wright OR. Prevalence of osteoporosis in prostate cancer survivors II: a metaanalysis of men not on androgen deprivation therapy. Endocrine 2015 50 344-354. (https://doi.org/10.1007/s12020-015-0536-7)

142 Lassemillante AC, Doi SA, Hooper JD, Prins JB \& Wright OR. Prevalence of osteoporosis in prostate cancer survivors: a metaanalysis. Endocrine 201445 370-381. (https://doi.org/10.1007/ s12020-013-0083-z)

143 Taylor LG, Canfield SE \& Du XL. Review of major adverse effects of androgen-deprivation therapy in men with prostate cancer. Cancer 2009115 2388-2399. (https://doi.org/10.1002/cncr.24283)

144 Shahinian VB, Kuo YF, Freeman JL \& Goodwin JS. Risk of fracture after androgen deprivation for prostate cancer. New England Journal of Medicine 2005352 154-164. (https://doi.org/10.1056/ NEJMoa041943)

145 Serpa Neto A, Tobias-Machado M, Esteves MA, Senra MD, Wroclawski ML, Fonseca FL, Dos Reis RB, Pompeo AC \& Giglio AD. Bisphosphonate therapy in patients under androgen deprivation therapy for prostate cancer: a systematic review and meta-analysis. Prostate Cancer and Prostatic Diseases 201215 36-44. (https://doi. org/10.1038/pcan.2011.4)

146 Smith MR, Egerdie B, Hernandez Toriz N, Feldman R, Tammela TL, Saad F, Heracek J, Szwedowski M, Ke C, Kupic A et al. Denosumab in men receiving androgen-deprivation therapy for prostate cancer. New England Journal of Medicine 2009361 745-755. (https://doi. org/10.1056/NEJMoa0809003)

147 Pontiroli AE, Miele L \& Morabito A. Increase of body weight during the first year of intensive insulin treatment in type 2 diabetes: systematic review and meta-analysis. Diabetes, Obesity and Metabolism 201113 1008-1019. (https://doi.org/10.1111/j.14631326.2011.01433.x)

148 Hermansen K \& Davies M. Does insulin detemir have a role in reducing risk of insulin-associated weight gain? Diabetes, Obesity and Metabolism 20079 209-217. (https://doi.org/10.1111/j.14631326.2006.00665.x)

149 WILDING J. Thiazolidinediones, insulin resistance and obesity: finding a balance. International Journal of Clinical Practice $2006 \mathbf{6 0}$ 1272-1280. (https://doi.org/10.1111/j.1742-1241.2006.01128.x)

150 BERNSTEIN JG. Induction of obesity by psychotropic drugs. Annals of the New York Academy of Sciences 1987499 203-215. (https://doi. org/10.1111/j.1749-6632.1987.tb36212.x)

151 Serretti A \& Mandelli L. Antidepressants and body weight: a comprehensive review and meta-analysis. Journal of Clinical Psychiatry 201071 1259-1272. doi:10.4088/JCP.09r05346blu.

152 Allison DB, Mentore JL, Heo M, Chandler LP, Cappelleri JC, Infante MC \& Weiden PJ. Antipsychotic-induced weight gain: a comprehensive research synthesis. American Journal of Psychiatry 1999 156 1686-1696. (https://doi.org/10.1176/ajp.156.11.1686)

153 Ben-Menachem E. Weight issues for people with epilepsy - a review. Epilepsia 200748 42-45. (https://doi.org/10.1111/j.15281167.2007.01402.x)

154 Wung PK, Anderson T, Fontaine KR, Hoffman GS, Specks U, Merkel PA, Spiera R, Davis JC, St.Clair EW, McCune WJ et al. Effects of glucocorticoids on weight change during the treatment of Wegener's granulomatosis. Arthritis and Rheumatism $2008 \mathbf{5 9}$ 746-753. (https://doi.org/10.1002/art.23561)

155 Petersons CJ, Mangelsdorf BL, Jenkins AB, Poljak A, Smith MD, Greenfield JR, Thompson CH \& Burt MG. Effects of low-dose prednisolone on hepatic and peripheral insulin sensitivity, insulin secretion, and abdominal adiposity in patients with inflammatory rheumatologic disease. Diabetes Care 201336 2822-2829. (https:// doi.org $/ 10.2337 / \mathrm{dc} 12-2617)$

156 Larsen JR, Vedtofte L, Jakobsen MSL, Jespersen HR, Jakobsen MI, Svensson CK, Koyuncu K, Schjerning O, Oturai PS, Kjaer A et al. Effect of liraglutide treatment on prediabetes and overweight or obesity in clozapine- or olanzapine-treated patients with schizophrenia spectrum disorder. JAMA Psychiatry $2017 \mathbf{7 4}$ 719-728. (https://doi.org/10.1001/jamapsychiatry.2017.1220)

157 Ikramuddin S, Korner J, Lee WJ, Thomas AJ, Connett JE, Bantle JP, Leslie DB, Wang Q, Inabnet 3rd WB, Jeffery RW et al. Lifestyle intervention and medical management with vs without Roux-en-Y gastric bypass and control of hemoglobin A1c, LDL cholesterol, and systolic blood pressure at 5 years in the diabetes surgery study. JAMA 2018319 266-278. (https://doi.org/210.1001/jama.2017.20813)

158 Lipscombe LL, Levesque L, Gruneir A, Fischer HD, Juurlink DN, Gill SS, Herrmann N, Hux JE, Anderson GM \& Rochon PA. Antipsychotic drugs and hyperglycemia in older patients with diabetes. Archives of Internal Medicine 2009169 1282-1289. (https:// doi.org/10.1001/archinternmed.2009.207)

159 Henderson DC, Cagliero E, Gray C, Nasrallah RA, Hayden DL, Schoenfeld DA \& Goff DC. Clozapine, diabetes mellitus, weight gain, and lipid abnormalities: a five-year naturalistic study. American Journal of Psychiatry 2000157 975-981. (https://doi.org/10.1176/ appi.ajp.157.6.975) 
160 Henderson DC. Clozapine: diabetes mellitus, weight gain, and lipid abnormalities. Journal of Clinical Psychiatry 200162 (Supplement 23) $39-44$.

161 Gianfrancesco FD, Grogg AL, Mahmoud RA, Wang RH \& Nasrallah HA. Differential effects of risperidone, olanzapine, clozapine, and conventional antipsychotics on type 2 diabetes: findings from a large health plan database. Journal of Clinical Psychiatry 200263 920-930. (https://doi.org/10.4088/JCP. v63n1010)

162 Lieberman JA, Stroup TS, McEvoy JP, Swartz MS, Rosenheck RA, Perkins DO, Keefe RS, Davis SM, Davis CE, Lebowitz BD et al. Effectiveness of antipsychotic drugs in patients with chronic schizophrenia. New England Journal of Medicine 2005353 1209-1223. (https://doi.org/10.1056/NEJMoa051688)

163 Nicol GE, Yingling MD, Flavin KS, Schweiger JA, Patterson BW, Schechtman KB \& Newcomer JW. Metabolic effects of antipsychotics on adiposity and insulin sensitivity in youths: a randomized clinical trial. JAMA Psychiatry 201875 788-796. (https://doi.org/10.1001/ jamapsychiatry.2018.1088)

164 McIntyre RS, McCann SM \& Kennedy SH. Antipsychotic metabolic effects: weight gain, diabetes mellitus, and lipid abnormalities. Canadian Journal of Psychiatry 200146 273-281. (https://doi. org/10.1177/070674370104600308)

165 Koller EA, Cross JT, Doraiswamy PM \& Malozowski SN. Pancreatitis associated with atypical antipsychotics: from the Food and Drug Administration's MedWatch surveillance system and published reports. Pharmacotherapy 200323 1123-1130. (https://doi. org/10.1592/phco.23.10.1123.32759)

166 Akhtar S, Kelly C, Gallagher A \& Petrie JR. Review: Newer antipsychotic agents, carbohydrate metabolism and cardiovascular risk. British Journal of Diabetes and Vascular Disease 20044 303-309. (https://doi.org/10.1177/14746514040040050301)

167 Lustman PJ, Griffith LS, Clouse RE, Freedland KE, Eisen SA, Rubin EH, Carney RM \& McGill JB. Effects of nortriptyline on depression and glycemic control in diabetes: results of a doubleblind, placebo-controlled trial. Psychosomatic Medicine 199759 241-250. (https://doi.org/10.1097/00006842-199705000-00007)

168 Maheux P, Ducros F, Bourque J, Garon J \& Chiasson JL. Fluoxetine improves insulin sensitivity in obese patients with non-insulindependent diabetes mellitus independently of weight loss. International Journal of Obesity and Related Metabolic Disorders 199721 97-102. (https://doi.org/10.1038/sj.ijo.0800372)

169 Michelson D, Amsterdam JD, Quitkin FM, Reimherr FW, Rosenbaum JF, Zajecka J, Sundell KL, Kim Y \& Beasley Jr CM. Changes in weight during a 1-year trial of fluoxetine. American Journal of Psychiatry 1999156 1170-1176.

170 Dagogo-Jack S. Atypical antipsychotic and antidepressant agents. In Diabetes Risks from Prescription and Nonprescription Drugs: Mechanisms and Approaches to Risk Reduction ch. Atypical antipsychotic and antidepressant agents, pp 75-83. Ed American Diabetes Association. Alexandria, Virginia, USA: American Diabetes Association, 2016.

171 Bonaventura A \& Montecucco F. Steroid-induced hyperglycemia: an underdiagnosed problem or clinical inertia? A narrative review. Diabetes Research and Clinical Practice 2018139 203-220. (https://doi. org/10.1016/j.diabres.2018.03.006)

172 van Raalte DH, Ouwens DM \& Diamant M. Novel insights into glucocorticoid-mediated diabetogenic effects: towards expansion of therapeutic options? European Journal of Clinical Investigation 200939 81-93. (https://doi.org/10.1111/j.1365-2362.2008.02067.x)

173 Liu XX, Zhu XM, Miao Q, Ye HY, Zhang ZY \& Li YM. Hyperglycemia induced by glucocorticoids in nondiabetic patients: a meta-analysis. Annals of Nutrition and Metabolism 201465 324-332. (https://doi. org $/ 10.1159 / 000365892)$

174 Gulliford MC, Charlton J \& Latinovic R. Risk of diabetes associated with prescribed glucocorticoids in a large population. Diabetes Care 200629 2728-2729. (https://doi.org/10.2337/dc06-1499)
175 van Raalte DH \& Diamant M. Steroid diabetes: from mechanism to treatment? Netherlands Journal of Medicine 201472 62-72.

176 Tamez-Perez HE, Quintanilla-Flores DL, Rodriguez-Gutierrez R, Gonzalez-Gonzalez JG \& Tamez-Pena AL. Steroid hyperglycemia: prevalence, early detection and therapeutic recommendations: a narrative review. World Journal of Diabetes 20156 1073-1081. (https://doi.org/10.4239/wjd.v6.i8.1073)

177 American Diabetes Association. 14. Diabetes care in the hospital: standards of medical care in diabetes-2018. Diabetes Care 201841 S144-S151. (https://doi.org/10.2337/dc18-S014)

178 Pichardo-Lowden AR, Fan CY \& Gabbay RA. Management of hyperglycemia in the non-intensive care patient: featuring subcutaneous insulin protocols. Endocrine Practice 201117 249-260. (https://doi.org/10.4158/EP10220.RA)

179 Roberts A, James J, Dhatariya K \& Joint British Diabetes Societies (JBDS) for Inpatient Care. Management of hyperglycaemia and steroid (glucocorticoid) therapy: a guideline from the Joint British Diabetes Societies (JBDS) for inpatient care group. Diabetic Medicine 201835 1011-1017. (https://doi.org/10.1111/dme.13675)

180 Taylor EN, Hu FB \& Curhan GC. Antihypertensive medications and the risk of incident type 2 diabetes. Diabetes Care 200629 1065-1070. (https://doi.org/10.2337/diacare.2951065)

181 Laakso M \& Kuusisto J. Diabetes secondary to treatment with statins. Current Diabetes Reports 201717 10. (https://doi.org/10.1007/s11892017-0837-8)

182 Gadelha MR, Bronstein MD, Brue T, Coculescu M, Fleseriu M, Guitelman M, Pronin V, Raverot G, Shimon I, Lievre KK et al. Pasireotide versus continued treatment with octreotide or lanreotide in patients with inadequately controlled acromegaly (PAOLA): a randomised, phase 3 trial. Lancet: Diabetes and Endocrinology 20142 875-884. (https://doi.org/10.1016/S22138587(14)70169-X)

183 Lew S \& Chamberlain RS. Risk of metabolic complications in patients with solid tumors treated with mTOR inhibitors: meta-analysis. Anticancer Research 201636 1711-1718.

184 Jain V, Patel RK, Kapadia Z, Galiveeti S, Banerji M \& Hope L. Drugs and hyperglycemia: a practical guide. Maturitas 2017104 80-83. (https://doi.org/10.1016/j.maturitas.2017.08.006)

185 Feingold K, Brinton EA \& Grunfeld C. The effect of endocrine disorders on lipids and lipoproteins. [Updated $2017 \mathrm{Feb} 24]$. In: KR Feingold, B Anawalt, A Boyce et al., editors. Endotext [Internet]. South Dartmouth (MA): MDText.com, Inc.; 2000-. Available from: https:/www.ncbi.nlm.nih.gov/books/NBK409608/

186 Anagnostis P, Galanis P, Chatzistergiou V, Stevenson JC, Godsland IF, Lambrinoudaki I, Theodorou M \& Goulis DG. The effect of hormone replacement therapy and tibolone on lipoprotein (a) concentrations in postmenopausal women: a systematic review and meta-analysis. Maturitas 201799 27-36. (https://doi.org/10.1016/j. maturitas.2017.02.009)

187 Herink M \& Ito MK. Medication induced changes in lipid and lipoproteins. [Updated 2018 May 10]. In: KR Feingold, B Anawalt, A Boyce et al. (Eds) Endotext [Internet]. South Dartmouth (MA): MDText.com, Inc.; 2000-. Available from: https://www.ncbi.nlm.nih. gov/books/NBK326739/

188 Sitruk-Ware R \& Nath A. Characteristics and metabolic effects of estrogen and progestins contained in oral contraceptive pills. Best Practice and Research: Clinical Endocrinology and Metabolism 201327 13-24. (https://doi.org/10.1016/j.beem.2012.09.004)

189 Isidori AM, Giannetta E, Greco EA, Gianfrilli D, Bonifacio V, Isidori A, Lenzi A \& Fabbri A. Effects of testosterone on body composition, bone metabolism and serum lipid profile in middleaged men: a meta-analysis. Clinical Endocrinology 200563 280-293. (https://doi.org/10.1111/j.1365-2265.2005.02339.x)

190 Corona G, Giagulli VA, Maseroli E, Vignozzi L, Aversa A, Zitzmann M, Saad F, Mannucci E \& Maggi M. THERAPY of ENDOCRINE DISEASE: Testosterone supplementation and body 
composition: results from a meta-analysis study. European Journal of Endocrinology 2016174 R99-R116. (https://doi.org/10.1530/EJE15-0262)

191 Ruige JB, Ouwens DM \& Kaufman JM. Beneficial and adverse effects of testosterone on the cardiovascular system in men. Journal of Clinical Endocrinology and Metabolism 201398 4300-4310. (https:// doi.org/10.1210/jc.2013-1970)

192 Alexander GC, Iyer G, Lucas E, Lin D \& Singh S. Cardiovascular risks of exogenous testosterone use among men: a systematic review and meta-analysis. American Journal of Medicine 2017130 293-305. (https://doi.org/10.1016/j.amjmed.2016.09.017)

193 Choi HK \& Seeger JD. Glucocorticoid use and serum lipid levels in US adults: the third National Health and Nutrition Examination Survey. Arthritis and Rheumatism 200553 528-535. (https://doi.org/10.1002/ art.21329)

194 Xiao C, Dash S, Morgantini C, Adeli K \& Lewis GF. Gut peptides are novel regulators of intestinal lipoprotein secretion: experimental and pharmacological manipulation of lipoprotein metabolism. Diabetes 201564 2310-2318. (https://doi.org/10.2337/db14-1706)

195 Del Olmo-Garcia MI \& Merino-Torres JF. GLP-1 receptor agonists and cardiovascular disease in patients with Type 2 diabetes. Journal of Diabetes Research 20182018 4020492. (https://doi. org $/ 10.1155 / 2018 / 4020492)$

196 Verges B, Duvillard L, Pais de Barros JP, Bouillet B, Baillot-Rudoni S, Rouland A, Sberna AL, Petit JM, Degrace P \& Demizieux L. Liraglutide reduces postprandial hyperlipidemia by increasing ApoB48 (apolipoprotein B48) catabolism and by reducing ApoB48 production in patients with type 2 diabetes mellitus. Arteriosclerosis, Thrombosis, and Vascular Biology 201838 2198-2206. (https://doi.org/10.1161/ ATVBAHA.118.310990)

197 Rosenblit PD. Common medications used by patients with type 2 diabetes mellitus: what are their effects on the lipid profile? Cardiovascular Diabetology 201615 95. (https://doi.org/10.1186/ s12933-016-0412-7)

198 Cha SA, Park YM, Yun JS, Lim TS, Song KH, Yoo KD, Ahn YB \& Ko SH. A comparison of effects of DPP-4 inhibitor and SGLT2 inhibitor on lipid profile in patients with type 2 diabetes. Lipids in Health and Disease 2017 16 58. (https://doi.org/10.1186/s12944-0170443-4)

199 Auchus RJ \& Arlt W. Approach to the patient: the adult with congenital adrenal hyperplasia. Journal of Clinical Endocrinology and Metabolism 201398 2645-2655. (https://doi.org/10.1210/ jc.2013-1440)

200 Han TS, Walker BR, Arlt W \& Ross RJ. Treatment and health outcomes in adults with congenital adrenal hyperplasia. Nature Reviews: Endocrinology 201410 115-124. (https://doi.org/10.1038/ nrendo.2013.239)

201 Reisch N, Arlt W \& Krone N. Health problems in congenital adrenal hyperplasia due to 21-hydroxylase deficiency. Hormone Research in Paediatrics 201176 73-85. (https://doi.org/10.1159/000327794)

202 Paragliola RM, Torino F, Papi G, Locantore P, Pontecorvi A \& Corsello SM. Role of mitotane in adrenocortical carcinoma - review and state of the art. European Endocrinology 201814 62-66. (https:// doi.org/10.17925/EE.2018.14.2.62)

203 Schteingart DE. Drugs in the medical treatment of Cushing's syndrome. Expert Opinion on Emerging Drugs 2009 14 661-671. (https://doi.org/10.1517/14728210903413522)

204 Sibal L, Jovanovic A, Agarwal SC, Peaston RT, James RA, Lennard TW, Bliss R, Batchelor A \& Perros P. Phaeochromocytomas presenting as acute crises after beta blockade therapy. Clinical Endocrinology 200665 186-190. (https://doi.org/10.1111/j.13652265.2006.02571.x)

205 Lenders JW, Duh QY, Eisenhofer G, Gimenez-Roqueplo AP, Grebe SK, Murad MH, Naruse M, Pacak K, Young Jr WF \& Endocrine Society. Pheochromocytoma and paraganglioma: an endocrine society clinical practice guideline. Journal of Clinical Endocrinology and Metabolism 201499 1915-1942. (https://doi.org/10.1210/ jc.2014-1498)

206 Guillemot J, Compagnon P, Cartier D, Thouennon E, Bastard C, Lihrmann I, Pichon P, Thuillez C, Plouin PF, Bertherat J et al. Metoclopramide stimulates catecholamine- and granin-derived peptide secretion from pheochromocytoma cells through activation of serotonin type 4 (5-HT4) receptors. Endocrine-Related Cancer 2009 16 281-290. (https://doi.org/10.1677/ERC-08-0190)

207 Rosas AL, Kasperlik-Zaluska AA, Papierska L, Bass BL, Pacak K \& Eisenhofer G. Pheochromocytoma crisis induced by glucocorticoids: a report of four cases and review of the literature. European Journal of Endocrinology 2008158 423-429. (https://doi. org/10.1530/EJE-07-0778)

208 Geva GA, Gross DJ, Mazeh H, Atlan K, Ben-Dov IZ \& Fischer M. Adrenocorticotropic hormone secreting pheochromocytoma underlying glucocorticoid induced pheochromocytoma crisis. Case Reports in Endocrinology 20182018 3963274. (https://doi. org/10.1155/2018/3963274)

209 Yi DW, Kim SY, Shin DH, Kang YH \& Son SM. Pheochromocytoma crisis after a dexamethasone suppression test for adrenal incidentaloma. Endocrine 201037 213-219. (https://doi.org/10.1007/ s12020-009-9303-y)

210 Fourman LT \& Fazeli PK. Neuroendocrine causes of amenorrhea - an update. Journal of Clinical Endocrinology and Metabolism 2015100 812-824. (https://doi.org/10.1210/jc.2014-3344)

211 Sklar CA, Mertens AC, Mitby P, Whitton J, Stovall M, Kasper C, Mulder J, Green D, Nicholson HS, Yasui Y et al. Premature menopause in survivors of childhood cancer: a report from the childhood cancer survivor study. Journal of the National Cancer Institute 200698 890-896. (https://doi.org/10.1093/jnci/djj243)

212 Rashid H, Ormerod S \& Day E. Anabolic androgenic steroids: what the psychiatrist needs to know. Advances in Psychiatric Treatment 2007 13 203-211. (https://doi.org/10.1192/apt.bp.105.000935)

213 Pope Jr HG, Wood RI, Rogol A, Nyberg F, Bowers L \& Bhasin S. Adverse health consequences of performance-enhancing drugs: an Endocrine Society scientific statement. Endocrine Reviews 201435 341-375. (https://doi.org/10.1210/er.2013-1058)

214 Joy E, De Souza MJ, Nattiv A, Misra M, Williams NI, Mallinson RJ, Gibbs JC, Olmsted M, Goolsby M, Matheson G et al. 2014 female athlete triad coalition consensus statement on treatment and return to play of the female athlete triad. Current Sports Medicine Reports 201413 219-232. (https://doi.org/10.1249/JSR.0000000000000077)

215 Nieschlag E \& Vorona E. MECHANISMS IN ENDOCRINOLOGY: Medical consequences of doping with anabolic androgenic steroids: effects on reproductive functions. European Journal of Endocrinology 2015173 R47-R58. (https://doi.org/10.1530/EJE-15-0080)

216 Mesbah F, Bordbar H, Talaei Khozani T, Dehghani F \& Mirkhani H. The non-preventive effects of human menopausal gonadotropins on ovarian tissues in nandrolone decanoate-treated female rats: a histochemical and ultra-structural study. International Journal of Reproductive Biomedicine 201816 159-174. (https://doi.org/10.29252/ ijrm.16.3.159)

217 Cherici Camargo IC, Barreiros de Souza R, de Fatima Paccola Mesquita S, Chuffa LG \& Frei F. Ovarian histology and follicular score in female rats treated with nandrolone decanoate and submitted to physical effort. Acta Biologica Hungarica 200960 253-261. (https:// doi.org/10.1556/ABiol.60.2009.3.2)

218 Simao VA, Berloffa Belardin L, Araujo Leite GA, de Almeida Chuffa LG \& Camargo IC. Effects of different doses of nandrolone decanoate on estrous cycle and ovarian tissue of rats after treatment and recovery periods. International Journal of Experimental Pathology 201596 338-349. (https://doi.org/10.1111/iep.12144)

219 Kanayama G, Brower KJ, Wood RI, Hudson JI \& Pope Jr HG. Treatment of anabolic-androgenic steroid dependence: emerging evidence and its implications. Drug and Alcohol Dependence 2010109 6-13. (https://doi.org/10.1016/j.drugalcdep.2010.01.011) 
220 Pope Jr HG, Kanayama G, Athey A, Ryan E, Hudson JI \& Baggish A. The lifetime prevalence of anabolic-androgenic steroid use and dependence in Americans: current best estimates. American Journal on Addictions 201423 371-377. (https://doi.org/10.1111/j.15210391.2013.12118.x)

221 Gruber AJ \& Pope Jr HG. Psychiatric and medical effects of anabolicandrogenic steroid use in women. Psychotherapy and Psychosomatics 200069 19-26. (https://doi.org/10.1159/000012362)

222 Pope HG, Kanayama G, Ionescu-Pioggia M \& Hudson JI. Anabolic steroid users' attitudes towards physicians. Addiction 200499 1189-1194. (https://doi.org/10.1111/j.1360-0443.2004.00781.x)

223 Loriaux DL. An approach to the patient with hirsutism. Journal of Clinical Endocrinology and Metabolism 201297 2957-2968. (https:// doi.org/10.1210/jc.2011-2744)

224 Neraud B \& Dewailly D. Drug-Induced Hyperandrogenism. Contemporary Endocrinology. Humana Press, 2006.

225 Basson R. Testosterone therapy for reduced libido in women. Therapeutic Advances in Endocrinology and Metabolism 20101 155-164. (https://doi.org/10.1177/2042018810379588)

226 Panjari M, Bell RJ, Jane F, Wolfe R, Adams J, Morrow C \& Davis SR. A randomized trial of oral DHEA treatment for sexual function, wellbeing, and menopausal symptoms in postmenopausal women with low libido. Journal of Sexual Medicine 20096 2579-2590. (https://doi. org/10.1111/j.1743-6109.2009.01381.x)

227 Verrotti A, D’Egidio C, Mohn A, Coppola G, Parisi P \& Chiarelli F. Antiepileptic drugs, sex hormones, and PCOS. Epilepsia 201152 199-211. (https://doi.org/10.1111/j.1528-1167.2010.02897.x)

228 Tauboll E, Gregoraszczuk EL, Wojtowicz AK \& Milewicz T. Effects of levetiracetam and valproate on reproductive endocrine function studied in human ovarian follicular cells. Epilepsia $2009 \mathbf{5 0}$ 1868-1874. (https://doi.org/10.1111/j.1528-1167.2009.02131.x)

229 Svalheim S, Sveberg L, Mochol M \& Tauboll E. Interactions between antiepileptic drugs and hormones. Seizure 201528 12-17. (https:// doi.org/10.1016/j.seizure.2015.02.022)

230 Ness-Abramof R \& Apovian CM. Drug-induced weight gain. Drugs of Today 200541 547-555. (https://doi.org/10.1358/ dot.2005.41.8.893630)

231 Isojarvi JI, Laatikainen TJ, Pakarinen AJ, Juntunen KT \& Myllyla VV. Polycystic ovaries and hyperandrogenism in women taking valproate for epilepsy. New England Journal of Medicine 1993329 1383-1388. (https://doi.org/10.1056/NEJM199311043291904)

232 Nelson-DeGrave VL, Wickenheisser JK, Cockrell JE, Wood JR, Legro RS, Strauss 3rd JF \& McAllister JM. Valproate potentiates androgen biosynthesis in human ovarian theca cells. Endocrinology 2004145 799-808. (https://doi.org/10.1210/en.2003-0940)

233 Wood JR, Nelson-Degrave VL, Jansen E, McAllister JM, Mosselman S $\&$ Strauss 3rd JF. Valproate-induced alterations in human theca cell gene expression: clues to the association between valproate use and metabolic side effects. Physiological Genomics 200520 233-243. (https://doi.org/10.1152/physiolgenomics.00193.2004)

234 Bilo L \& Meo R. Polycystic ovary syndrome in women using valproate: a review. Gynecological Endocrinology 200824 562-570. (https://doi.org/10.1080/09513590802288259)

235 Hu X, Wang J, Dong W, Fang Q, Hu L \& Liu C. A meta-analysis of polycystic ovary syndrome in women taking valproate for epilepsy. Epilepsy Research 201197 73-82. (https://doi.org/10.1016/j. eplepsyres.2011.07.006)

236 Creasy DM. Pathogenesis of male reproductive toxicity. Toxicologic Pathology 200129 64-76. (https://doi. org/10.1080/019262301301418865)
237 Ly LP, Liu PY \& Handelsman DJ. Rates of suppression and recovery of human sperm output in testosterone-based hormonal contraceptive regimens. Human Reproduction 200520 1733-1740. (https://doi. org/10.1093/humrep/deh834)

238 Meriggiola MC \& Bremner WJ. Progestin-androgen combination regimens for male contraception. Journal of Andrology $1997 \mathbf{1 8}$ $240-244$.

239 Gacci M, Carini M, Salvi M, Sebastianelli A, Vignozzi L, Corona G, Maggi M, McVary KT, Kaplan SA, Oelke M et al. Management of benign prostatic hyperplasia: role of phosphodiesterase-5 inhibitors. Drugs and Aging 201431 425-439. (https://doi.org/10.1007/s40266014-0177-1)

240 Basaria S, Jasuja R, Huang G, Wharton W, Pan H, Pencina K, Li Z, Travison TG, Bhawan J, Gonthier R et al. Characteristics of men who report persistent sexual symptoms after finasteride use for hair loss. Journal of Clinical Endocrinology and Metabolism 2016101 4669-4680. (https://doi.org/10.1210/jc.2016-2726)

241 Safarinejad MR. Sperm DNA damage and semen quality impairment after treatment with selective serotonin reuptake inhibitors detected using semen analysis and sperm chromatin structure assay. Journal of Urology 2008180 2124-2128. (https://doi.org/10.1016/j. juro.2008.07.034)

242 Clayton AH, Pradko JF, Croft HA, Montano CB, Leadbetter RA, Bolden-Watson C, Bass KI, Donahue RM, Jamerson BD \& Metz A. Prevalence of sexual dysfunction among newer antidepressants. Journal of Clinical Psychiatry 200263 357-366. (https://doi. org/10.4088/JCP.v63n0414)

243 Giwercman A \& Lundberg Giwercman Y. Hypogonadism in young men treated for cancer. Hormones 201514 590-597. (https://doi. org/10.14310/horm.2002.1650)

244 Millsop JW, Heller MM, Eliason MJ \& Murase JE. Dermatological medication effects on male fertility. Dermatologic Therapy 201326 337-346. (https://doi.org/10.1111/dth.12069)

245 Hoeltzenbein M, Weber-Schoendorfer C, Borisch C, Allignol A, Meister R \& Schaefer C. Pregnancy outcome after paternal exposure to azathioprine/6-mercaptopurine. Reproductive Toxicology 201234 364-369. (https://doi.org/10.1016/j. reprotox.2012.05.001)

246 Eisenberg ML, Li S, Cullen MR \& Baker LC. Increased risk of incident chronic medical conditions in infertile men: analysis of United States claims data. Fertility and Sterility 2016105 629-636. (https://doi. org/10.1016/j.fertnstert.2015.11.011)

247 Graf KJ, Schmidt-Gollwitzer M, Horowski R \& Dorow R. Effect of metoclopramide and lisuride on hypophyseal and gonadal function in men. Clinical Endocrinology 198217 243-251. (https://doi. org/10.1111/j.1365-2265.1982.tb01586.x)

248 Smarr MM, Grantz KL, Sundaram R, Maisog JM, Honda M, Kannan K \& Buck Louis GM. Urinary paracetamol and time-to-pregnancy. Human Reproduction 201631 2119-2127. (https://doi.org/10.1093/ humrep/dew172)

249 Albert O, Desdoits-Lethimonier C, Lesne L, Legrand A, Guille F, Bensalah K, Dejucq-Rainsford N \& Jegou B. Paracetamol, aspirin and indomethacin display endocrine disrupting properties in the adult human testis in vitro. Human Reproduction 201328 1890-1898. (https://doi.org/10.1093/humrep/det112)

250 Schooling CM, Au Yeung SL, Freeman G \& Cowling BJ. The effect of statins on testosterone in men and women, a systematic review and meta-analysis of randomized controlled trials. BMC Medicine 201311 57. (https://doi.org/10.1186/17417015-11-57)

Received 3 March 2019

Revised version received 25 April 2019

Accepted 3 June 2019 